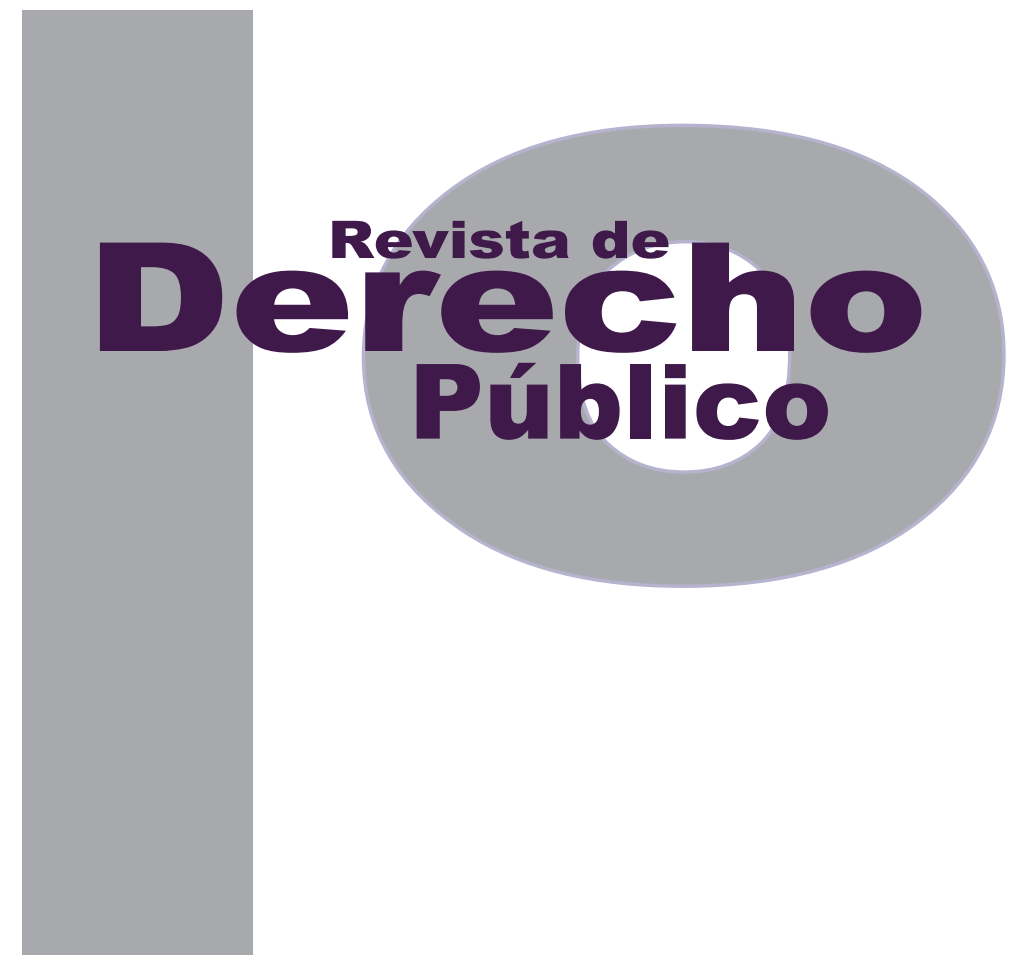

\title{
ANÁLISIS DE LAS POSICIONES DE ALGUNOS PAÍSES EN DESARROLLO, EN LAS NEGOCIACIONES SOBRE LA ENMIENDA DE LA PROHIBICIÓN AL CONVENIO DE BASILEA
}

JUAN JOSÉ REYES GóMEZ

Universidad de los Andes

Facultad de Derecho

Revista de Derecho Público N. ${ }^{\circ} 29$

Julio - Diciembre de 2012. ISSN 1909-7778 


\title{
Análisis de las posiciones de algunos países en desarrollo, en las negociaciones sobre la enmienda de la prohibición al convenio de basilea
}

\author{
Juan José Reyes Gómez*
}

\begin{abstract}
RESUMEN
La investigación tiene como fin analizar cómo las diferencias de posición que existen entre países en desarrollo hacen que estos no tengan una postura uniforme y coherente en las negociaciones de algunos tratados ambientales en el sistema multilateral ambiental. Para ello, se tomará como ejemplo la evolución de las posiciones que han tenido Chile, Colombia, Costa de Marfil y la India frente a la Enmienda de la Prohibición que ha sido objeto de discusiones por más de quince años en las Conferencias de las Partes del Convenio de Basilea, el cual regula los movimientos transfronterizos de desechos peligrosos. El proyecto se enfocará en el tema de la Enmienda al Convenio de Basilea que busca prohibir los movimientos transfronterizos de desechos peligrosos desde los países más desarrollados hacia los países en desarrollo.
\end{abstract}

Palabras clave: Convenio de Basilea, Enmienda de la Prohibición, desechos peligrosos, desechos electrónicos, comercio, medio ambiente, desarrollo sostenible, países desarrollados, países en desarrollo.
The purpose of this investigation is to analyze how the differences which exist in the positions held by developing countries have stopped them from maintaining a common position in relation with the Basel Ban Amendment. For such purpose, the analysis will be focused in determining the factors that have influenced the positions held by Chile, Colombia, Cote d'Ivoire and India towards the Basel Ban Amendment which has been the subject of negotiations that have taken place for more than 15 years in the meetings of the Conference of the Parties of the Basel Convention. The Basel Convention regulates the movements of hazardous waste between nations and the Basel Ban Amendment has the aim of prohibiting the transfer of hazardous waste from developed to developing countries.

KEY WORDS: Basel Convention, Basel Ban Amendment, hazardous waste, E-waste, business, environment, sustainable development, developed countries, developing countries. 


\section{SUMARIO}

Introducción - Objetivo general y pregunta de investigación - Objetivos específicos - I. INTRODUCCIÓN GENERAL AL CONVENIO DE BASILEA - A. Objetivos y obligaciones generales del Convenio de Basilea - B. Definición de desechos peligrosos en el marco del Convenio de Basilea - C. El concepto de "eliminación" en el Convenio de Basilea - D. La Enmienda al Convenio de Basilea (Enmienda de la Prohibición) - 1. La Prohibición que establece la Enmienda - 2. Posibles factores que incidieron en que los países en desarrollo actuaran como un bloque al apoyar la Decisión III/1 del 22 de septiembre de 1995 mediante la cual se adoptó la Enmienda de la Prohibición - 3. Discusión sobre la interpretación del artículo 17 del Convenio de Basilea y otros obstáculos que han impedido la entrada en vigor de la Enmienda de la Prohibición - II. CONTEXTUALIZACIÓN DE LOS PAÍSES OBJETO DE ESTUDIO Y LA EVOLUCIÓN DE LA POSICIÓN DE CADA UNO DE ELLOS FRENTE A LA ENMIENDA AL CONVENIO DE BASILEA - A. El caso de Chile - 1. Economía orientada hacia el libre mercado y primer país en Suramérica en hacerse parte de la OCDE - 2. El ingreso de Chile a la OCDE coincide con la decisión de finalmente ratificar la Enmienda al Convenio de Basilea - B. El caso de Colombia - 1. Posibilidades que representa el negocio del reciclaje2. La legislación interna - 3. La iniciativa legislativa - 4. La posición de Colombia - C. El caso de Costa de Marfil - 1. Una economía dependiente - 2. El manejo inadecuado de desechos peligrosos y la debilidad institucional - D. El caso de la India - 1. Una oportunidad de negocios asociada con la entrada al país de desechos peligrosos - 2. El caso del portaaviones francés "Clemenceau" - III. POSIBLES FACTORES QUE HAN IMPEDIDO MANTENER UNA POSICIÓN COMÚN POR PARTE DE LOS PAÍSES EN ESTUDIO FRENTE A LA ENMIENDA AL CONVENIO DE BASILEA - A. Consideraciones con base en las cuales se esperaría que los países en desarrollo actuaran como bloque frente a la Enmienda al Convenio de Basilea-B. Posibles factores económicos y políticos que han influido en las posiciones de los países en estudio frente a la Enmienda de la Prohibición - IV. RESULTADOS DE LA 10a CONFERENCIA DE LAS PARTES DEL CONVENIO DE BASILEA REALIZADA EN CARTAGENA EN OCTUBRE DE 2011 - V. CONCLUSIONES - VI. ANEXOS - Bibliografía. 
Introducción

\section{Objetivo general y pregunta} de investigación

Este trabajo tiene como fin analizar si existen diferencias entre países en desarrollo, que hagan que estos no tengan una posición uniforme y coherente en el contexto de las negociaciones del sistema multilateral ambiental. Para ello, se tomará como ejemplo la evolución de las posiciones que han tenido Chile, Colombia, Costa de Marfil y la India frente a la Enmienda de la Prohibición, que ha sido objeto de discusiones por más de quince años en las distintas reuniones de la Conferencia de las Partes del Convenio de Basilea, el tratado que regula los movimientos transfronterizos de desechos peligrosos ${ }^{2}$. Con lo anterior se buscará determinar si las diferencias entre países en desarrollo, frente a factores como la estabilidad política, el grado de industrialización, la riqueza en recursos naturales, entre otros, ha llevado a que estos tengan intereses distintos y por ende no actúen como un bloque en el marco de las negociaciones de algunos tratados ambientales en el sistema multilateral ambiental. En este sentido, las preguntas de investigación que se buscan resolver son las siguientes: ¿Cuáles son los elementos principales que marcan las diferencias en las posiciones que han tenido los países en estudio frente a la Enmienda al Convenio de Basilea? y ¿Qué implicaciones tiene la existencia de estas diferencias en el contexto de las negociaciones multilaterales?

2 Convenio de Basilea sobre el Control de los Movimientos Transfronterizos de Desechos Peligrosos y su Eliminación. Artículos 1 y 2 .
La Enmienda al Convenio de Basilea busca prohibir los movimientos transfronterizos de desechos peligrosos desde los países más desarroIlados hacia los países en desarrollo ${ }^{3}$. Dicha modificación del texto se conoce como la Enmienda de la Prohibición y aún no ha entrado en vigor, debido, en parte, a que los países en desarrollo no tienen una misma posición frente a la conveniencia de ratificarla. Es importante aclarar que los países en desarrollo sí tuvieron una posición común cuando se adoptó la Enmienda de la Prohibición en 1995 y las diferencias surgieron posteriormente frente a la conveniencia de ratificarla; es más, países en desarrollo como la India han encontrado con el tiempo que el reciclaje les representa importantes oportunidades de negocios y motivados por este interés se han mostrado en contra de su ratificación.

Incluso para los países desarrollados, el manejo adecuado de desechos peligrosos presenta un reto importante no solo por los altos costos sino por la complejidad de los procedimientos involucrados en esta labor. ${ }^{4}$ Por lo tanto, ante la situación de vulnerabilidad en que se encuentran los países en desarrollo respecto a este tema, sería lógico que tuvieran una posición coherente para enfrentar esta problemática en las negociaciones internacionales ambientales. En este punto, es relevante mencionar que en la selección de los países en estudio se tuvo en cuenta la división geopolítica no oficial en que se encuentran los Estados miembros de las Naciones Unidas -

3 Decisión III/1 del 22 de septiembre de 1995, adoptada durante la Tercera Reunión de la Conferencia de las Partes del Convenio de Basilea (COP 3) que tuvo lugar en Ginebra. Basel Action Network. Documental: Exportar el peligro: Asia bajo la Basura Al-Tec. 
Chile y Colombia pertenecen al GRULAC (The Latin American and Caribbean Group), Costa de Marfil pertenece al Grupo Africano, y la India hace parte del Grupo Asiático- con el fin de enriquecer el análisis desde el punto de vista del derecho internacional ambiental.

\section{Objetivos específicos}

a) Identificar los objetivos y obligaciones generales del Convenio de Basilea.

b) Explicar en qué consiste la Enmienda al Convenio de Basilea (Enmienda de la Prohibición).

c) Identificar los antecedentes de la Enmienda de la Prohibición.

d) Analizar los posibles factores que incidieron en que los países objeto de este estudio actuaran como un bloque al apoyar la Decisión III/1 del 22 de septiembre de 1995 mediante la cual se adoptó la Enmienda de la Prohibición.

e) Identificar los obstáculos que han impedido la entrada en vigor de la Enmienda al Convenio de Basilea.

f) Identificar el contexto específico de Chile, CoIombia, India y Costa de Marfil en relación con el tratamiento de desechos peligrosos.

g) Identificar la evolución de las posiciones de estos países en desarrollo frente a la Enmienda de la Prohibición. h) Explorar las posibles implicaciones de la $10^{\mathrm{a}}$ Conferencia de las Partes del Convenio de Basilea, realizada en Cartagena, en relación con la Enmienda.

Metodología

En el desarrollo de esta investigación se acudió a diferentes fuentes de información: noticias publicadas en distintos medios de comunicación; documentos relacionados con el desarrollo de las nueve Conferencias de las Partes del Convenio de Basilea que antecedieron la $10^{\mathrm{a}}$ Conferencia realizada en Cartagena (Colombia) en octubre del 2011 y el material que se distribuyó en esta última; así como documentales que tratan la problemática del manejo inadecuado de desechos en América Latina, Asia y África, entre otros.

También se tuvo en cuenta la información oficial de la Secretaría del Convenio de Basilea y la información nacional aportada por los gobiernos. Por otro lado, es importante destacar que tuve la oportunidad de participar, como parte del personal de apoyo, en la $10^{\mathrm{a}}$ Conferencia de las Partes del Convenio de Basilea (en adelante COP 10) y pude estar presente en algunas de las plenarias y en las reuniones del GRULAC, lo que me permitió obtener información relevante para esta investigación.

Adicionalmente, se logró una entrevista con la oNG Basel Action Network (BAN), organización no gubernamental cuyo objetivo es combatir la exportación de desechos tóxicos, desechos tecnológicos y productos tóxicos desde países altamente industrializados hacia países en de- 
sarrollo. Además, se recibieron aportes de los funcionarios del Ministerio de Ambiente y Desarrollo Sostenible de la República de Colombia, con competencia en el tema del Convenio de Basilea.

\section{INTRODUCCIÓN GENERAL AL CONVENIO DE BASILEA}

\section{A. Objetivos y obligaciones generales del Convenio de Basilea}

El Convenio de Basilea sobre el Control de los Movimientos Transfronterizos de los Desechos Peligrosos y su Eliminación, en adelante 'el Convenio', es un tratado multilateral ambiental que tiene como objetivos principales: a) evitar al máximo el movimiento transfronterizo de los desechos, b) disminuir la producción de desechos y c) prohibir el envío de desechos peligrosos a países que no tengan la capacidad legal, técnica o administrativa para manejarlos. ${ }^{5}$

Con respecto a las principales obligaciones del Convenio, este utiliza la herramienta que se conoce como pic por sus siglas en inglés (Prior Informed Consent $)^{6}$, que consiste en la obligación de preguntar e informar al país al cual se van a enviar los desechos, con el objeto de que la autoridad competente decida si los recibe o no. Esta obligación tiene como fin permitir que los

unep. Basel Convention. Waste without frontiers. Global trends in generation and transboundary movements of hazardous wastes and other wastes. Analysis of the data from national reporting to the Secretariat of the Basel Convention for the years 2004-2006. Pág. 5.

6 PNUmA. Convenio de BAsilea. Manual de capacitación sobre el tráfico ilícito para los servicios de aduanas y organismos encargados de hacer cumplir la ley. Francia, abril de 2011. Pág. 7. países cuenten con la posibilidad de evaluar las consecuencias para la salud humana y el medio ambiente antes de aprobar un movimiento de desechos peligrosos.

\section{B. Definición de desechos peligrosos en el marco del Convenio de Basilea}

La expresión "desechos peligrosos" hace referencia

\begin{abstract}
a desechos sólidos, líquidos o gaseosos, o a una combinación de ellos que, debido a su cantidad, concentración, composición o características químicas, pueden presentar un peligro real o potencial para la salud humana o para el medio ambiente cuando son tratados, almacenados, transportados o eliminados de forma inadecuada, o manejados de otra manera inapropiada. ${ }^{7}$
\end{abstract}

En el artículo 1. a) del Convenio se establece lo que se entiende por desechos peligrosos: "Los desechos que pertenezcan a cualquiera de las categorías enumeradas en el Anexo I, a menos que no tengan ninguna de las características descritas en el Anexo III."

En el Anexo I se enumeran los desechos resultantes de actividades como la atención médica, la industria farmacéutica, la industria fotográfica, etc., con los códigos Y1 a Y18 y los desechos que tienen determinados componentes, como cadmio, plomo, arsénico, entre otros, con los códigos Y19 a Y45. El objetivo de los códigos es

\footnotetext{
7 PNUmA. Convenio de BAsilea. Manual de capacitación sobre el tráfico ilícito para los servicios de aduanas y organismos encargados de hacer cumplir la ley. Francia, abril de 2011. Pág. 9.

8 Convenio de Basilea. Artículo 1. a).
} 
facilitar la identificación de los desechos y por lo tanto es obligatorio incluirlos en los documentos que deben acompañar todo movimiento transfronterizo de estos. ${ }^{9}$

En cuanto al Anexo III, este incluye una lista de características peligrosas que presentan riesgos debido a los efectos que pueden tener esa(s) sustancia(s) o mezclas de sustancias. Dichas características se refieren, por ejemplo, al potencial explosivo o inflamable, a la producción de gases inflamables o tóxicos, por citar algunas, y se han identificado con los códigos $\mathrm{H} 1 \mathrm{a}$ H13. Cuando los desechos que se enumeran en el Anexo I no tienen ninguna de las características señaladas en el Anexo III, no se les aplicarán las obligaciones establecidas en el Convenio de Basilea. No obstante, dichos desechos pueden ser abarcados por el párrafo 1.b) del artículo 1 del Convenio. Dicho párrafo establece que "desechos peligrosos" son también los desechos no incluidos en el apartado a), pero definidos o considerados peligrosos por la legislación interna de la Parte que sea Estado de exportación, de importación o de tránsito. De acuerdo con lo dispuesto en el artículo 3 del Convenio, todo Estado Parte que en virtud de su legislación nacional considere peligrosos desechos distintos de los que figuran en los Anexos I y II, deberá informar de ello a la Secretaría del Convenio. ${ }^{10}$

\section{El concepto de "eliminación" en el}

9 PNUmA. ConvenIo DE BASILEA. Manual de capacitación sobre el tráfico ilícito para los servicios de aduanas y organismos encargados de hacer cumplir la ley. Francia, abril de 2011. Pág. 10.

10 PNUmA. Convenio de BAsilea. Manual de capacitación sobre el tráfico ilícito para los servicios de aduanas y organismos encargados de hacer cumplir la ley. Francia, abril de 2011. Pág. 10.
Convenio de Basilea

Es importante destacar que el Convenio de Basilea no se limita a regular los movimientos transfronterizos de desechos peligrosos; también incluye disposiciones relacionadas con su eliminación: "El método de eliminación no solo concierne al país de importación, sino que también tiene repercusiones legales para el país de exportación (donde se ubica el generador). Con el Convenio de Basilea se pretende garantizar que dicha eliminación se realice de una forma ambientalmente racional"11. En este punto, se debe aclarar que el concepto de "eliminación" también hace referencia a operaciones que pueden conducir a la recuperación de recursos, al reciclaje o a la reutilización de los desechos. ${ }^{12}$

\section{La Enmienda al Convenio de Basilea (Enmienda de la Prohibición)}

\section{La prohibición que establece la Enmienda}

En el marco de la Decisión III/1 del 22 de septiembre de 1995, durante la COP 3 que tuvo lugar en Ginebra, las Partes adoptaron una Enmienda al Convenio conocida como Enmienda de la Prohibición, que consiste en prohibir las exportaciones de residuos peligrosos destinados a su eliminación definitiva así como las exportaciones de residuos peligrosos destinados a operaciones de valorización, desde los Estados

\footnotetext{
11 PNUmA. Convenio de BAsilea. Manual de capacitación sobre el tráfico ilícito para los servicios de aduanas y organismos encargados de hacer cumplir la ley. Francia, abril de 2011. Pág. 11.

12 Convenio de Basilea. Anexo IV, Apartado B
} 
que figuran en el Anexo VII del Convenio, es decir, "Ios miembros de la Organización para la Cooperación y el Desarrollo Económicos (OCDE), de la CE (Comisión Europea) y de Liechtenstein", hacia Ios Estados no enumerados en el Anexo VII del Convenio, es decir, los países en desarrollo. ${ }^{13}$

\section{Posibles factores que incidieron en que los países en desarrollo actuaran como un bloque al apoyar la Decisión III/1 del 22 de septiembre de 1995 mediante la cual se adoptó la Enmienda de la Prohibición}

Según Jim Puckett, actual director ejecutivo de la ong Basel Action Network, desde que surgió el Convenio, uno de los objetivos deseados por los países en desarrollo era lograr el establecimiento de la prohibición de realizar movimientos transfronterizos de desechos peligrosos desde los países desarrollados hacia los países en desarrollo. ${ }^{14}$ En 1994, los países en desarrollo, contando con el apoyo de la organización Greenpeace, persuadieron a la cop 2 de llegar a un acuerdo para prohibir las exportaciones de desechos peligrosos desde los países miembros de la OCDE hacia los países que para entonces no eran parte de dicha organización. ${ }^{15}$ Lo anterior indica que los países en desarrollo actuaron como bloque en esa oportunidad (1994), lo cual finalmente condujo a la adopción de la Enmienda de la Prohibición durante la cop 3, en 1995.

13 Convenio de Basilea. Anexo VII

14 Puckett, Jim. The Basel Treaty's Ban on Hazardous Waste Exports: An Unfinished Success Story. Artículo publicado en el año 2000. Encontrado en: http://ban.org/library/ierarticle.html. Consulta realizada el 19 de abril de 2012.

15 BIRNIE, Patricia and Boyle, Alan. International Law and the Environment. Second Edition. Oxford: Oxford University Press. 2002. Pág. 429.
Katharina Kummer, actualmente funcionaria de la Secretaría del Convenio, describe cómo la polémica con relación a las exportaciones de desechos peligrosos desde los países más desarrollados hacia los países en desarrollo se acentuó en la década de 1980:

A mediados de la década de los 80 , el debate político sobre la cuestión del transporte internacional de desechos peligrosos en general, $y$ del tráfico transfronterizo ilegal de dichos desechos en particular, fue ganando impulso, y alcanzó su punto álgido en 1988 con la amplia publicidad que dieron los medios de información a distintos incidentes de vertido ilegal en países del Tercer Mundo de desechos tóxicos procedentes de naciones industrializadas. ${ }^{16}$

El siguiente fragmento del artículo de Katharina Kummer antes citado también evidencia que los países en desarrollo actuaron como un bloque en las negociaciones que dieron origen al Convenio:

Durante el proceso de negociación del Convenio de Basilea la opinión pública centró su atención casi exclusivamente en el aspecto "Norte-Sur" del problema (...) Un importante número de países en desarrollo, encabezados por los Estados miembros de la Organización de la Unidad Africana (ovA), la predecesora de la Unión Africana, consideraron que las deliberaciones les daban la oportunidad de demostrar su solidaridad, negándose a tolerar que sus territorios fueran utilizados como vertederos para los desechos tóxicos de Estados ricos

Kummer, Katharina. Convenio de Basilea sobre el control de los movimientos transfronterizos de los desechos peligrosos y su eliminación. United Nations Audiovisual Library of International Law. 2011. Pág. 2. Encontrado en: http://untreaty.un.org/cod/avl/pdf/ha/ bcctmhwd/bcctmhwd_s.pdf. Consulta realizada el 21 de abril de 2012. 
del mundo industrializado. Su petición de que se prohibiera completamente todo movimiento transfronterizo de desechos peligrosos en todo el mundo recibió un gran apoyo de las organizaciones ecologistas no gubernamentales. Por su parte, muchos países desarrollados, que preferían la posibilidad de controlar el tráfico de desechos, no estaban dispuestos a aceptar ningún tipo de medida que impusiera demasiadas restricciones al comercio de desechos. ${ }^{17}$

Algunos de los principios consagrados en la Declaración de Río, adoptada en la Conferencia de las Naciones Unidas sobre Medio Ambiente y Desarrollo (CNUMAD), realizada en Río de Janeiro en junio de 1992, constituyen un factor influyente en el hecho de que los países en desarrollo actuaran como un bloque al adoptar la Enmienda de la Prohibición. ${ }^{18}$ Por ejemplo, se considera que el Principio 14 de la Declaración de Río contribuyó de manera importante a que los países en desarrollo tuvieran una posición común frente a la Enmienda de la Prohibición. ${ }^{19}$ Este principio establece que "los Estados deberían cooperar efectivamente para desalentar o evitar la reubicación y la transferencia a otros Estados de cualesquiera actividades y sustancias que causen degradación ambiental grave o se consideren nocivas para la salud humana."20 En suma, en la CNUMAD los gobiernos adoptaron por primera vez de manera oficial el concepto

17 Ibidem

18 Exposición de Motivos del proyecto de ley presentado ante el Congreso de Colombia en el año 2011, tendiente a buscar la ratificación de la Enmienda al Convenio de Basilea.

19 BIRNIE, Patricia and Boyle, Alan. International Law and the Environment. Second Edition. Oxford University Press. Oxford. 2002. Pág. 429.

Declaración de Río de 1992. Principio 14 de desarrollo sostenible. ${ }^{21}$ Con respecto a dicho concepto, el Principio 4 de la Declaración de Río afirma que "a fin de alcanzar el desarrollo sostenible, la protección del medio ambiente deberá constituir parte integrante del proceso de desarrollo."22 Mostrarse a favor de la Enmienda de la Prohibición en 1995 puede verse entonces como una oportunidad que aprovecharon los países en desarrollo para demostrar que estaban actuando de manera coherente con el concepto de desarrollo sostenible contenido en la Declaración de Río de 1992.

Hablando específicamente de los países en estudio, la Enmienda al Convenio de Basilea fue aceptada en 1995 por Chile, India y Costa de Marfil, en el marco de la cop $3 .{ }^{23}$ Colombia, que entonces no era Parte del Convenio, no estuvo representada en esta Conferencia pero su ratificación se dio un año después mediante la Ley 253 de 1996, indicando que para este entonces el país estaba de acuerdo con la Enmienda de la Prohibición.

21 URIBE, Diego y CÁRDEnAs, Fabián Augusto. Derecho Internacional Ambiental. Primera Edición. Universidad Jorge Tadeo Lozano. Bogotá, 2010. Pág. 247. Declaración de Río de 1992. Principio 4.

23 Ban. The Basel Ban Amendment: Just Say Now! Briefing paper 4. October 2011. 


\section{Discusión sobre la interpretación del artículo 17 del Convenio de Basilea y otros obstáculos que han impedido la en- trada en vigor de la Enmienda de la Prohi- bición}

El procedimiento para la entrada en vigor de una enmienda se encuentra consagrado en el artículo 17 del Convenio de Basilea. El párrafo 3 de este artículo establece que "una vez agotados todos los esfuerzos por lograr un consenso sin que se haya llegado a un acuerdo, la enmienda se adoptará, como último recurso, por mayoría de tres cuartos de las Partes presentes y votantes en la reunión, y será presentada a todas las Partes por el Depositario para su ratificación, aprobación, confirmación formal o aceptación". En suma, el párrafo 5 del artículo 17 del Convenio establece lo siguiente: "Las enmiendas adoptadas de conformidad con los párrafos 3 o 4 de este artículo entrarán en vigor, respecto de las Partes que las hayan aceptado, el nonagésimo día después de la fecha en que el Depositario haya recibido el instrumento de su ratificación, aprobación, confirmación formal o aceptación por tres cuartos, como mínimo, de las Partes que hayan aceptado las enmiendas al protocolo de que se trate, salvo si en este se ha dispuesto otra cosa". La expresión "de las Partes que hayan aceptado" ha generado un conflicto en cuanto a la interpretación del artículo, como se explica a continuación.

Para entrar en vigor la enmienda debe cumplir con los requisitos establecidos en el artículo 17, a los que se hizo referencia en el párrafo anterior. No obstante, existe una discusión de carácter procedimental que ha impedido que la Enmienda entre en vigor. Dicha discusión versa sobre el número de Partes requeridas para ratificarla. Algunos países consideran que se necesita que tres cuartos de las Partes presentes en el día de la adopción de la Enmienda la ratifiquen. De acuerdo con esta primera interpretación del artículo 17, basta con la ratificación de 62 de las Partes para que la Enmienda entre en vigor. Otros países consideran que para la entrada en vigor de la Enmienda es necesario que tres cuartas partes de las Partes de la Convención la ratifiquen. La Convención tiene 175 Partes en total, es decir, que bajo esta segunda interpretación del artículo 17 se necesitaría la ratificación por más de 132 de las Partes. Hasta el momento, 73 Partes han ratificado la Enmienda al Convenio. ${ }^{24}$

En adición a las anteriores dos posibles interpretaciones del artículo 17 existe una tercera, que se conoce como el enfoque del "tiempo corregido". Esta expresión hace referencia a que la Enmienda de la Prohibición entraría en vigor cuando se logren 12 ratificaciones adicionales del grupo conformado por los 32 países que estaban presentes en 1995, cuando se adoptó la Enmienda, y que aún no la han ratificado. ${ }^{25}$ Esta tercera opción con relación a la interpretación del artículo 17 del Convenio surgió como resultado de una iniciativa liderada por los gobiernos de Suiza e Indonesia, que se conoce con las siglas CLI (Country-Led Initiative) ${ }^{26}$. El grupo

\footnotetext{
24 Basel Action Network. The Basel Ban Amendment: Just Say Now! Briefing Paper 4. October 2011.

25 Ibidem.

26 Indonesian-Swiss Country Led Initiative (CLI) to improve the
} 
conformado por los 32 países, de los cuales se requiere al menos 12 ratificaciones para que la Enmienda de la Prohibición entre en vigor de acuerdo con el enfoque del "tiempo corregido", se encuentra en la tabla $B$ ), incluida en la parte de Anexos al final del documento.

El Reporte de la cop 8, realizada en Nairobi en 2006, describe la discusión de carácter procedimental antes mencionada. En el párrafo 34 de este documento se destaca cómo la Unión Europea ha insistido, reiteradamente, en la necesidad de interpretar el artículo 17 del Convenio, de tal forma que se permitiera la entrada en vigor de la Enmienda de la Prohibición cuando, para ese momento, 63 de las Partes la habían ratificado. ${ }^{27}$ De acuerdo con los argumentos expuestos por la Comunidad Europea, para el año 2006 la Enmienda de la Prohibición ya estaba siendo aplicada por varios de sus Estados miembros y arrojando resultados exitosos en cuanto a la capacidad de evitar perjuicios para los países en desarrollo, asociados con los movimientos transfronterizos de desechos peligrosos. Vale la pena mencionar que en dicha ocasión, el representante de la Comunidad Europea también habló en nombre de Rumania y Bulgaria, países que se encontraban próximos a unirse a la UE, lo cual indica que estos dos Estados estaban a

effectiveness of the Basel Convention. Explanatory Note. CLI/2010/3/2. Disponible en: https://docs.google.com/viewer? $\mathrm{a}=\mathrm{v} \& \mathrm{q}=$ cache:dF8Ck DZpSwJ:archive.basel.int/convention/cli/documents/explanatorynote-17-12-2010.doc $+C L I / 2010 / 3 / 2 \& h l=e s \& g l=c o \&$ pid=bl\&srcid=ADG EESj1T8OIV-n7FHw1WaQZWbAY246XGIx7u0mfK65JGwWtgGhmSF 7HutLTGDckScLx_EYYCRkd-eNSBP5pFhXI-aSnXt07DYy2TX_3vEI3 o78Q2Z2okZmLFaZYGaJVLiUrUI42xnbD\&sig=AHIEtbSQSYGIH6RT ZyJGpUmax9iJ2ZRiEw

27 Informe de la Conferencia de las Partes del Convenio de Basilea en su octava reunión. Nairobi, 27 de noviembre - 1 de diciembre de 2006. Párrafo 34. Disponible en: http://archive.basel.int/meetings/cop/cop8/ docs/16eREISSUED.pdf. favor de acelerar la entrada en vigor de la Enmienda de la Prohibición.

El Reporte del Grupo de Trabajo del Convenio de Basilea, en su sexta sesión realizada en septiembre de 2007, resalta cómo para este año un número significativo de las Partes todavía no había ratificado la Enmienda de la Prohibición. De los países que para el 2007 no la habían ratificado, cuarenta eran de África, diecinueve de Asia y veintiuno de América Latina y el Caribe. ${ }^{28}$

Aparte de la discusión de tipo procedimental anteriormente descrita, hay otras razones que han obstaculizado la entrada en vigor de la Enmienda al Convenio de Basilea. Por ejemplo, países en desarrollo como la India, motivados por factores económicos, no están interesados en que la Enmienda entre en vigor. Además, algunos países han expresado que la prohibición que establece la Enmienda implica asumir, injustificadamente, que los países que no son miembros de la OCDE no tienen ni pueden adquirir la capacidad para lograr un manejo adecuado de los desechos. En concordancia con este argumento, los países que se oponen a la Enmienda afirman que a través de ella se les está negando a los países en desarrollo la posibilidad de participar en el mercado mundial en materia de reciclaje y se les impide beneficiarse del uso de algunos desechos como materia prima para procesos productivos. Fuera de esto, algunos de los países que no quieren que la Enmienda entre en vigor sostienen que la prohibición que esta impone

\footnotetext{
28 Informe del Grupo de Trabajo del Convenio de Basilea en su sexta sesión. Ginebra, 3 a 7 de septiembre de 2007. UNEP/CHW/ OEWG/6/29. Párrafo 26. Disponible en: http://archive.basel.int/ meetings/oewg/oewg6/docs/29e.pdf
} 
contradice el principio de "no discriminación" de la Organización Mundial del Comercio. ${ }^{29}$

\section{CONTEXTUALIZACIÓN DE LOS PAÍ- SES OBJETO DE ESTUDIO Y LA EVOLU- CIÓN DE LA POSICIÓN DE CADA UNO DE ELLOS FRENTE A LA ENMIENDA AL CONVENIO DE BASILEA}

\section{A. El caso de Chile}

\section{Economía orientada hacia el libre mer- cado y primer país en Suramérica en ha- cerse parte de la OCDE}

La economía de Chile está orientada hacia el libre mercado y en ella juega un papel de gran importancia el comercio exterior. Evidencia de lo anterior es el hecho de que es el país que más ha ratificado tratados de comercio bilateral o regional. Siendo más preciso, Chile ha firmado tratados comerciales con Estados Unidos, la Unión Europea, Mercosur, China, India, Corea del Sur, México, entre otros. Por otro lado, entre los principales productos de exportación de Chile se destaca el cobre, que representa un tercio de los ingresos del gobierno. El crecimiento de la economía chilena ha estado acompañado por una reducción significativa de los índices de pobreza en las últimas décadas. Por consiguiente, en el año 2009, la OCDE lo invitó a ser miembro de la organización y en mayo de 2010 Chile depositó el instrumento de adhesión a la Conven-

29 Puckett, Jim. The Basel Ban: A Triumph Over Business-As-Usual. Encontrado en: http://ban.org/about_basel_ban/jims_article.html. Consulta realizada el 14 de mayo de 2012 ción de la oCDE, constituyéndose en el primer país de Suramérica en hacerse parte de esta. ${ }^{30}$

Es importante precisar que la oCDE es considerada un 'club' de países ricos y su objetivo principal es "buscar la armonización de políticas públicas que generen crecimiento económico, empleo y mejora en las condiciones de vida." ${ }^{31}$ Los requisitos para ser parte de esta organización se resumen a continuación: “El principal requisito para ingresar demanda un compromiso en promover la democracia, el respeto a los derechos humanos y una economía de mercado. Dicho esto, no se necesita ser 'rico' para entrar a tan selecto grupo, aunque la gran mayoría de sus miembros hagan parte de las economías con mayor nivel de desarrollo." 32

\section{El ingreso de Chile a la OCDE coincide con la decisión de finalmente ratificar la Enmienda al Convenio de Basilea}

Luego de que Chile ratificó el Convenio de Basilea, en 1992, se presentó un proyecto de ley que buscaba prohibir la importación de desechos peligrosos. No obstante, dicho proyecto de ley no fue aprobado por el Congreso chileno. ${ }^{33} \mathrm{En}$

30 CIA. World Factbook. Chile. Encontrado en: https://www.cia.gov/ library/publications/the-world-factbook/geos/br.html. Consulta realizada el 3 de marzo de 2012

31 Portafolio. Colombia en la OECD: Un propósito nacional. Encontrado en: http://www.portafolio.co/archivo/documento/ CMS-4117869. Consulta realizada el 3 de marzo de 2012.

$32 \quad$ Ibidem

33 Banco Interamericano de Desarrollo. Fortalecimiento de la gestión ambiental para cumplimiento de acuerdos multilaterales ambientales (AmUMA's). Mayo, 2007. Pág. 22. Encontrado en: http://idbdocs.iadb. org/wsdocs/getdocument.aspx?docnum=1001426. Consulta realizada el 3 de marzo de 2012 
este punto, vale la pena citar el siguiente fragmento del documento Fortalecimiento de la gestión ambiental para cumplimiento de acuerdos multilaterales ambientales (AмumA's), publicado en el año 2007, en el que se describe cómo, prohibir la importación de desechos peligrosos en Chile, sería una medida contraria a los intereses de la industria del cobre en este país: "La aprobación de este Convenio ha afectado al Sector Minero Chileno ya que ha dificultado la importación desde mercados internacionales de "productos" tales como chatarra de cobre, desechos de yodos, chatarra electrónica y los barros anódicos - entre otros insumos." ${ }^{34} \mathrm{En}$ el documento antes citado también se menciona que Chile es exportador de varios desechos peligrosos incluyendo, por ejemplo, baterías de plomo y barros anódicos (concentrado de metales preciosos) que se exportan a Europa, principalmente a Bélgica. ${ }^{35}$ Tras ingresar a la oCDE en mayo de 2010, Chile finalmente ratificó la Enmienda de la Prohibición mediante el Decreto Supremo No. 264 del 16 de abril de 2011. ${ }^{36}$ Esto indica que en el ingreso de Chile a la ocDE un factor influyente fue la decisión de ratificar la Enmienda de la Prohibición.

34 Ibidem. Pág. 24.

35 Ibidem. Pág. 24.

36 Chile. Congreso Nacional. Decreto Supremo No. 264 del 16 de abril de 2011.
B. El caso de Colombia

\section{Posibilidades que representa el negocio del reciclaje}

Con respecto al perfil económico del país, el gobierno actual ha hecho énfasis en cinco aspectos considerados pilares para estimular el crecimiento: las industrias extractivas de recursos naturales, la agricultura, la infraestructura, la vivienda de interés social y la innovación. De acuerdo con estadísticas del año 2009, la población que se encuentra bajo la línea de pobreza es de aproximadamente el $45.5 \%$. Por consiguiente, el desempleo y las grandes desigualdades entre riqueza y pobreza continúan siendo desafíos para la administración nacional. Así mismo, Colombia requiere mejoras significativas en infraestructura para lograr que el crecimiento económico sea sostenible. ${ }^{37}$

En el contexto de crecimiento económico en el que se encuentra actualmente Colombia, el mercado que se basa en usar los desechos como materia prima para procesos productivos se presenta como una oportunidad de negocios y podría ser coherente con el pilar de la innovación propuesto por el presidente Juan Manuel Santos. No obstante, factores como las evidentes debilidades en la infraestructura indican que el país no se encuentra preparado para darle un manejo adecuado a los desechos peligrosos, sin poner en riesgo el medio ambiente y por ende la salud de los ciudadanos.

37 CIA. The CIA World Factbook. Colombia. Encontrado en: https://www. cia.gov/library/publications/the-world-factbook/geos/co.html. Consulta realizada el 4 de diciembre de 2011. 


\section{La legislación interna}

El artículo 81 de la Constitución de Colombia establece: "queda prohibida la fabricación, importación, posesión y uso de armas químicas, biológicas y nucleares, así como la introducción al territorio nacional de residuos nucleares y desechos tóxicos." ${ }^{38}$ En este punto, es relevante mencionar que el término "desechos peligrosos" es el género mientras que los "desechos tóxicos" constituyen la especie. Por otro lado, es importante destacar que la Ley 1252 de 2008 prohíbe totalmente la entrada de desechos peligrosos al territorio nacional.

A pesar de las anteriores prohibiciones, según Alba Ávila (profesora de la Facultad de Ingeniería Electrónica de la Universidad de los Andes), en la actualidad entran a Colombia una cantidad significativa de desechos peligrosos a los que no se les da un manejo adecuado, a pesar de que se cuenta con las herramientas técnicas para determinar su grado de peligrosidad. ${ }^{39}$ Esto ha permitido identificar que, por ejemplo, el manejo de los aparatos electrónicos obsoletos representa un desafío para el país:

Exactamente las mismas tendencias también se pueden observar en Colombia. Las ventas de equipos eléctricos y electrónicos se han disparado en los últimos años, y es tan solo cuestión de tiempo hasta que estos aparatos serán descartados por sus usuarios y se convertirán en residuos. Frente a una disposición final in-

\footnotetext{
38 Constitución Política de Colombia de 1991, artículo 81.

39 La reunión con la profesora Alba Ávila tuvo lugar en las oficinas de la Facultad de Ingeniería Electrónica de la Universidad de los Andes, el día 7 de septiembre de 2011.
}

adecuada (i. e. relleno sanitario, incineración, procesos de reciclaje informales o artesanales), estos productos obsoletos se convierten en residuos potencialmente peligrosos y de alto impacto al medio ambiente y la salud humana debido a la presencia de algunos compuestos tóxicos en su estructura (i. e. metales pesados, plásticos con materiales pirorretardantes bromados) (...) Además hay pocas empresas formales que se dedican a reciclar e-waste y en cambio se estima una creciente proliferación de actividades "artesanales" de recuperación, bajo sistemas informales que no garantizan la protección de los trabajadores frente a la manipulación y exposición a materiales tóxicos. ${ }^{40}$

\section{La iniciativa legislativa}

Aunque el Convenio de Basilea fue ratificado por Colombia en 1996, solo hasta el año 2008 se presentó por primera vez ante el Congreso un proyecto de ley tendiente a ratificar la Enmienda de la Prohibición. ${ }^{41}$ Esta iniciativa legislativa no logró superar el trámite en el Congreso y la propuesta fue archivada. Sin embargo, hay argumentos para afirmar que el país debería ratificarla. Dentro de estos argumentos se encuentra el hecho de que la legislación vigente prohíbe la entrada de desechos peligrosos y que estos representan un riesgo para la biodiversidad del país y para la salud de los ciudadanos, debido a que Colombia no tiene la capacidad para manejarlos adecuadamente.

40 Отт, Daniel. Gestión de residuos electrónicos en Colombia: diagnóstico de computadores y teléfonos celulares. Medellín. 2008. Pág. 3. Encontrado en: http://www.swissinfo.ch/media/cms/files/ swissinfo/2008/07/gestion_residuos_electronicos_colombia.pdf. Consulta realizada el 12 de mayo de 2012.

41 Colombia. Senado de la República de Colombia. Proyecto de Ley número 151 de 2008. 
En septiembre de 2011, la ministra de Relaciones Exteriores y la ministra de Ambiente, Vivienda y Desarrollo Territorial presentaron nuevamente ante el Congreso un proyecto de ley encaminado a lograr la ratificación de la Enmienda de la Prohibición. Este hecho se produjo, en parte, debido a que la cop 10 se realizaría en Colombia en octubre de 2011. Por lo tanto, impulsar la ratificación de la Enmienda de la Prohibición por medio de un proyecto de ley fue una actuación coherente con el rol que tuvo Colombia en dicha instancia multilateral. En la Exposición de Motivos, que se aprobó en primer debate en la Comisión II del Senado, en noviembre de $2011,{ }^{42}$ se expresa la importancia de ratificar la Enmienda al Convenio de Basilea y se mencionan los siguientes aspectos como evidencia de las limitaciones que tiene Colombia con relación al manejo de desechos peligrosos:

- La tecnología de punta y manejo especializado que requiere la disposición, transporte y eliminación de los desechos peligrosos;

- La necesidad de mejorar la capacidad de las autoridades aduaneras para ejercer un efectivo control sobre las importaciones de residuos peligrosos;

- Las deficiencias de la infraestructura nacional para la caracterización y manejo de los desechos peligrosos generados en nuestro

42 Universidad de los Andes. Congreso Visible. Encontrado en: http://www.congresovisible.org/proyectos-de-ley/por-medio-dela-cual-se-aprueba-la-enmienda-al-convenio-de-basilea-sobreel-control-de-los-movimientos-transfronterizos-de-desechospeligrosos-y-su-eliminacion-del-22-de-marzo-de-1989-adoptadapor-la-tercera-reunion-de-la-conferencia-de-las-partes-enginebra-el-22-de-septiembre-de-1995-convenio-sobre-desechospeligrosos/6429/\#tab=2. Consulta realizada el 21 de abril de 2012 . propio territorio; existen inclusive corrientes de residuos peligrosos para los cuales no se tienen alternativas de gestión en el país a corto o mediano plazo;

Las limitaciones relativas a la capacidad técnica, operativa y de personal capacitado de que adolecen las autoridades ambientales, para la evaluación, control y seguimiento de las actividades de manejo de los desechos peligrosos. ${ }^{43}$

\section{La posición de Colombia}

En la cop 10 la delegación de Colombia manifestó su interés en realizar esfuerzos para que en dicha Conferencia se lograran resultados concretos, tendientes a la protección de los países en desarrollo frente a la amenaza que representan los desechos peligrosos. La posición anterior fue expuesta inicialmente, como es costumbre en las negociaciones ambientales, por los delegados de Colombia en la reunión del GRULAC, que se cumplió en el salón Barahona IV del Centro de Convenciones Cartagena de Indias, el 16 de octubre de 2011. Dicha reunión tuvo como propósito discutir el texto de la Declaración del GRULAC que se leería en la plenaria de la Conferencia el día siguiente. ${ }^{44}$

En conclusión, la delegación que representó al país en la cop 10 fue clara al expresar su interés

43 Exposición de Motivos del proyecto de ley presentado por la ministra de Relaciones Exteriores y la ministra de Ambiente, Vivienda y Desarrollo Territorial ante el Congreso de Colombia, el 7 de septiembre de 2011, con el objetivo de que se ratifique la Enmienda al Convenio de Basilea.

44 Tuve la oportunidad de estar presente en la reunión del GRULAC que se llevó a cabo el 16 de octubre de 2011, en el salón Barahona IV del Centro de Convenciones Cartagena de Indias. 
en lograr un acuerdo sobre la interpretación del artículo 17.5 del Convenio. Lo anterior se puede apreciar en el siguiente aparte del Resumen de la cop 10 publicado en el Boletín de Negociaciones de la Tierra:

El lunes la Secretaría presentó la cLı para mejorar la eficacia del Convenio de Basilea (UNEP/ chw.10/5). Suiza dijo que el proyecto de decisión de la cu incluye tres elementos que se apoyan mutuamente, a saber: la entrada en vigor de la Enmienda de Prohibición; directrices para la Gestión Ambientalmente Racional (GAR) de desechos peligrosos; y claridad legal en torno a las disposiciones del Convenio (...) En cuanto a la sección de la Enmienda de Prohibición de la decisión, la ue destacó su apoyo a la adopción de la interpretación jurídica del Artículo 17(5) propuesta en la cLI, que establece que la ratificación de una enmienda por tres cuartos de las Partes en el momento de la adopción de la enmienda (el enfoque del "tiempo corregido") es lo requerido para su entrada en vigor. CoIombia, Egipto e Irak también apoyaron el enfoque de "tiempo corregido". ${ }^{45}$

\section{El caso de Costa de Marfil}

\section{Una economía dependiente}

Costa de Marfil se caracteriza por ser dependiente en un alto grado de actividades relacionadas con la agricultura. Evidencia de lo anterior es que aproximadamente el $68 \%$ de la población se encuentra vinculada con este sector. El cacao, el aceite y el café son los productos de

45 Boletín de Negociaciones de la Tierra. Resumen de la $10^{\mathrm{a}}$ Conferencia de las Partes del Convenio de Basilea. Encontrado en: http://www.iisd. ca/vol20/enb2037s.html. Consulta realizada el 15 de abril de 2012. exportación que representan una mayor fuente de ingresos para el país, de ahí que un número considerable de inmigrantes, procedentes de países vecinos con niveles alarmantes de pobreza, se han asentado allí para trabajar principalmente en las plantaciones de cacao y café. ${ }^{46}$ De acuerdo con estadísticas del año 2006, la población que se encontraba bajo la línea de pobreza era, aproximadamente, el $42 \%{ }^{47}$

Teniendo en cuenta el contexto económico antes descrito, se esperaría que Costa de Marfil respaldara de manera clara la Enmienda de la Prohibición, considerando que le resulta de gran valor proteger sus recursos naturales dado que la exportación de varios productos agrícolas, entre los cuales se destaca el cacao, tiene una importancia significativa en su economía. Además, en el Reporte de la cop 8 se describe la situación de vulnerabilidad de Costa de Marfil frente al manejo de desechos peligrosos. Por ejemplo, en el párrafo 55 de este documento, se narra cómo una delegada hablando a nombre del grupo de países de África se refirió a Costa de Marfil para hacer énfasis en "la vulnerabilidad extrema de los Estados de África debido a su falta de recursos y capacidad de rastrear el movimiento de desechos peligrosos." 48

46 Bвc Mundo. Costa de Marfil, de país modelo a enfermo africano. Artículo publicado el 4 de enero de 2011. Encontrado en: http:// latercera.com/noticia/mundo/bbc-mundo/internacional/2011/01/1434335488-9-bbc-costa-de-marfil-de-pais-modelo-a-enfermo-africano. shtml. Consulta realizada el 25 de abril de 2012

47 CIA. World Factbook. Cote d'Ivoire. Encontrado en: https://www.cia. gov/library/publications/the-world-factbook/geos/iv.html. Consulta realizada el 4 de diciembre de 2011.

48 Informe de la Conferencia de las Partes del Convenio de Basilea en su octava reunión. Nairobi, 27 de noviembre - 1 de diciembre de 2006. Párrafo 55. Disponible en: http://archive.basel.int/meetings/cop/cop8/ docs/16s.pdf 


\section{El manejo inadecuado de desechos pe- ligrosos y la debilidad institucional}

Costa de Marfil es un país que ha sido afectado por el mal manejo de desechos peligrosos. Los sucesos ocurridos en el 2006, con relación a la llegada de desechos peligrosos a su territorio, indican que las autoridades locales no estaban preparadas para darle un manejo adecuado a dichos desechos. En el Reporte del Grupo de Trabajo del Convenio, en su sexta sesión realizada en septiembre de $2007,{ }^{49}$ se hace énfasis en los trágicos sucesos ocurridos en Costa de Marfil, donde fue evidente que los oficiales y los operadores de aduana en los puertos necesitaban entrenamiento para entender mejor los controles internacionales con relación al manejo de desechos. En el Reporte de la cop 8 se describe cómo Costa de Marfil solicitó el apoyo de la comunidad internacional para superar esta situación: "Hacía falta asistencia en materia de salud, agricultura, recursos pecuarios, rehabilitación de la capa freática, ayuda a las industrias, incluido el sector no estructurado, y la red de información, así como para las familias damnificadas. Costa de Marfil esperaba contar con la asistencia técnica y financiera de la comunidad internacional y con ayuda para la creación de capacidad y el intercambio de información." 50

49 Informe del Grupo de Trabajo del Convenio de Basilea en su sexta sesión. Ginebra, 3 a 7 de septiembre de 2007. unEP/CHw/OEWG/6/29. Párrafo 26. Disponible en: http://archive.basel.int/meetings/oewg/ oewg6/docs/29s.pdf

50 Informe de la Conferencia de las Partes del Convenio de Basilea en su octava reunión. Nairobi, 27 de noviembre - 1 de diciembre de 2006. Párrafo 27. Disponible en: http://archive.basel.int/meetings/cop/cop8/ docs/16s.pdf
En agosto del año 2006, residuos tóxicos a bordo del barco Probo Koala, fletados por la empresa petrolera holandesa Trafigura, fueron vertidos en la ciudad de Abiyán (capital comercial del país). Como consecuencia de esto, más de 100000 personas solicitaron atención médica y se registraron 15 muertes. En febrero de 2007, Trafigura firmó un acuerdo con el gobierno de Costa de Marfil en el que se comprometió a pagar la suma de 195 millones de dólares estadounidenses para cubrir la indemnización de las víctimas y los costos de la limpieza. Posteriormente, en septiembre de 2009, Trafigura hizo un pago adicional de 45 millones de dólares estadounidenses, en el marco de un acuerdo extrajudicial que se logró en el Reino Unido ante la presión que ejercieron más de 30000 marfileños que habían interpuesto una demanda por daños y perjuicios en relación con el vertido. No obstante, un grupo que se hacía llamar Coordinación Nacional de Víctimas de Residuos Tóxicos de Costa de Marfil y que afirmaba falsamente representar a las víctimas impidió la distribución justa de este dinero. Dicho grupo logró que un Tribunal de Costa de Marfil ordenara transferir a su cuenta bancaria los dineros que se debían distribuir entre las víctimas. Debido a esto, miles de personas afectadas por el vertido tóxico aún no han recibido la indemnización correspondiente. ${ }^{51}$ Esta situación refleja las deficiencias que existen en el funcionamiento del ordenamiento jurídico en Costa de Marfil.

\footnotetext{
51 Amnesty International. Costa de Marfil: El dinero perdido debe llegar a las víctimas del vertido tóxico de Trafigura. Encontrado en: http:// www.amnesty.org/en/node/26240. Artículo publicado el 19 de agosto de 2011. Consulta realizada el 4 de diciembre de 2011.
} 
A pesar de ser un ejemplo claro de un país en desarrollo afectado por el manejo inadecuado de desechos peligrosos, Costa de Marfil todavía no ha ratificado la Enmienda de la Prohibición, hecho que refleja la debilidad institucional que lo caracteriza: “Además, en cierto modo, lo que está sucediendo en Costa de Marfil pone de relieve no solo la debilidad del sistema político del país, sino que también muestra la falta de autoridad real de organismos regionales como la Unión Africana o la Comunidad Económica de Estados de África Occidental a la hora de aplicar soluciones diplomáticas a problemas políticos graves." 52 Con respecto a la debilidad institucional latente, vale la pena mencionar que el país ha sido afectado por una crisis política que se inició tras la muerte, en 1993, del presidente Houphouet-Boigny quien gobernó durante 33 años. A raíz de este suceso empezó a presentarse una marcada división entre el sur y el norte del país en aspectos étnicos, religiosos y económicos. ${ }^{53}$
52 BBC MUNDo. Costa de Marfil: Las profundas raíces de un conflicto que termina. Encontrado en: http://www.bbc.co.uk/mundo/ noticias/2011/04/110405_costa_marfil_contexto_conflicto_pea.shtml. Consulta realizada el 24 de abril de 2012.

53 BBC MUNDo. Costa de Marfil, de país modelo a enfermo africano. Artículo publicado el 4 de enero de 2011. Encontrado en: http://latercera.com/ noticia/mundo/bbc-mundo/internacional/2011/01/1434-335488-9-bbccosta-de-marfil-de-pais-modelo-a-enfermo-africano.shtml. Consulta realizada el 25 de abril de 2012 .

\section{El caso de la India}

\section{Una oportunidad de negocios asociada con la entrada al país de desechos peligrosos}

Las actividades económicas en la India incluyen agricultura bajo métodos tradicionales, agricultura con técnicas modernas, manufacturas, una gama amplia de industrias modernas y diversos servicios. Aproximadamente la mitad de la fuerza de trabajo se concentra en actividades vinculadas con la agricultura. Por otro lado, los servicios representan la fuente más importante de crecimiento económico, utilizando un tercio de la fuerza de trabajo disponible en el país. ${ }^{54}$

La India ha encontrado grandes posibilidades de negocios en temas como el reciclaje. Aunque en el año 1997 la Corte Suprema prohibió la importación de desechos peligrosos, una cantidad significativa de desechos tecnológicos (comúnmente conocidos en inglés como e-waste) ha seguido entrando al país. La expresión e-waste, hace referencia a equipos eléctricos y electrónicos que ya no son apropiados para ser utilizados o que la última persona en usarlos ha dejado de hacerlo destinándolos a su disposición final o a que sean reciclados. ${ }^{55}$ Frente a los movimientos transfronterizos de equipos eléctricos y electrónicos usados, bajo el Convenio de Basilea ha

\footnotetext{
54 THE CIA WORLD FACTBOOK. India. Encontrado en: https://www.cia. gov/library/publications/the-world-factbook/geos/in.html. Consulta realizada el 4 de diciembre de 2011.

55 Technical guidelines on transboundary movements of e-waste, in particular regarding the distinction between waste and non-waste. UNEP/CHW.10/28. Párrafo 9. Disponible en: http://archive.basel.int/ meetings/cop/cop10/documents/i05e.pdf
} 
surgido la necesidad de desarrollar directrices técnicas para hacer la distinción entre desechos y sustancias distintas de los desechos. En el Reporte de la cop 10 se hace alusión a la Decisión Bc-10/5 en la cual se describen los avances relacionados con la elaboración de dichas directrices. ${ }^{56} \mathrm{El}$ documento que contiene estos avances expresa que cuando un equipo eléctrico o electrónico usado se considere un desecho peligroso, según el artículo 1.1.a. del Convenio o de acuerdo con la legislación nacional (artículo 1.1.b. del Convenio), debe seguirse el procedimiento del Consentimiento Informado Previo (PIC) para transportarlo de un país a otro. ${ }^{57}$

En el año 2007, un estudio realizado por la Asociación de Manufactureros de Tecnologías de Información en conjunto con la Agencia Alemana para la Cooperación Técnica en la India, reveló que 50000 toneladas de desechos electrónicos provenientes de países desarrollados son importadas a la India. ${ }^{58}$ De acuerdo con el artículo antes citado, la ciudad de Seelampur, localizada a nueve millas de Nueva Delhi, es el lugar donde se concentra la mayor cantidad de desechos que llegan al país. Estos desechos tecnológicos son desmantelados manualmente por los trabajadores, quienes se ven expuestos a altos riesgos para la salud teniendo en cuenta que los

56 Decisión BC-10/5 en el marco de la COP 10. Disponible en: http:// archive.basel.int/meetings/cop/cop10/documents/28s.pdf

57 Technical guidelines on transboundary movements of e-waste, in particular regarding the distinction between waste and non-waste. UNEP/CHW.10/28. Párrafo 49. Disponible en: http://archive.basel.int/ meetings/cop/cop10/documents/i05e.pdf

58 Вношмıск, Nilanjana. Time World. Is India's E-Waste problem spiraling out of control? Encontrado en: http://www.time.com/time/world/ article/0,8599,2071920,00.html. Artículo publicado el 23 de mayo de 2011. Consulta realizada el 3 de diciembre de 2011. monitores de computadores, teclados, cables, cartuchos, bombillos, entre otros, son quemados al aire libre contaminando el ambiente con toxinas de plomo y mercurio. ${ }^{59}$ Esto se hace con el propósito de extraer partes que pueden ser reutilizadas, generando una buena oportunidad de negocio. ${ }^{60}$

El gobierno de la India ha hecho esfuerzos para reaccionar ante la situación antes descrita. Un ejemplo de ello es la planta de reciclaje más grande de la nación, que se está construyendo en terrenos del Estado, en Bangalore, y tendrá capacidad para reciclar aproximadamente 60 000 toneladas de desechos tecnológicos anualmente. ${ }^{61}$

\section{El caso del portaaviones francés "Clemenceau"}

Hay casos concretos que demuestran las limitaciones de la India con relación a la capacidad para manejar desechos peligrosos adecuadamente. Un ejemplo de ello lo constituye el caso del portaaviones francés "Clemenceau", que partió el 31 de diciembre de 2005 hacia el noroeste de la India con el objetivo de ser desguazado. Como resultado de la polémica generada

59 E-waste in India: A Growing Industry and Environmental Threat. Encontrado en: http://www.treehugger.com/clean-technology/ewaste-in-india-a-growing-industry-environmental-threat.html. Artículo publicado el 9 de octubre de 2007. Consulta realizada el 3 de diciembre de 2011.

60 BBC NEWs. Growing concern over India's e-waste. Encontrado en: http:// news.bbc.co.uk/2/hi/south_asia/3307815.stm. Artículo publicado el 12 de diciembre de 2003. Consulta realizada el 3 de diciembre de 2011.

61 Вношмıск, Nilanjana. Time World. Is India's E-Waste problem spiraling out of control? Encontrado en: http://www.time.com/time/world/ article/0,8599,2071920,00.html. Artículo publicado el 23 de mayo de 2011. Consulta realizada el 3 de diciembre de 2011. 
por las grandes cantidades de amianto y asbesto que contenía el buque, la Corte Suprema de la India prohibió su entrada al puerto. ${ }^{62}$ Luego, el presidente francés, Jacques Chirac, dio la orden de que el buque regresara a Francia. La decisión del tribunal de la India indica que el país efectivamente no tenía la capacidad para darle un manejo adecuado a estos desechos peligrosos.

En el documental Exportar el peligro: Asia bajo la Basura Al-Tec, se describen algunas razones de esta problemática: cómo en países desarrollados, por ejemplo en Estados Unidos, el reciclaje y la disposición final de los desechos electrónicos implican altos costos en particular por la mano de obra que se requiere; cómo la exportación de desechos peligrosos desde los países desarrollados hacia los países en desarrollo está basada en factores económicos y cómo el bajo costo de la mano de obra en Asia ha llevado a que países en desarrollo como la India y China reciban grandes cantidades de desechos tecnológicos provenientes de países desarrollados.

Así mismo, el documental expresa que aún en países desarrollados como los Estados Unidos es difícil dar un manejo adecuado a los desechos tecnológicos, que cumpla con la normatividad existente tendiente a proteger el medio ambiente y la salud humana y muestra la forma en que el manejo inadecuado que se le da a los desechos importados por Asia afecta de forma

62 Elmundo.es. La justicia india prohíbe la entrada del portaaviones francés Clemenceau. Encontrado en: http://www.elmundo.es/ elmundo/2006/01/16/ciencia/1137398670.html. Consulta realizada el 4 de marzo de 2012 alarmante el medio ambiente y la salud de las personas.

En suma, el contenido del documental indica que los altos niveles de pobreza en el Asia han llevado a que un número considerable de personas encuentre una forma de subsistencia en el desmantelamiento de desechos tecnológicos, a pesar de que ello les está ocasionando consecuencias perjudiciales para la salud y el entorno en el que habitan, afectando de forma negativa la calidad de vida. ${ }^{63}$ En este punto cabe mencionar que de acuerdo con estadísticas del año 2007, se estima que la población que se encuentra por debajo de la línea de pobreza en la India es aproximadamente el 25\%. ${ }^{64}$

\section{POSIBLES FACTORES QUE HAN IM- PEDIDO MANTENER UNA POSICIÓN COMÚN POR PARTE DE LOS PAÍSES EN ESTUDIO FRENTE A LA ENMIENDA AL CONVENIO DE BASILEA}

\section{A. Consideraciones con base en las cua- les se esperaría que los países en desa- rrollo actuaran como bloque frente a la Enmienda al Convenio de Basilea}

En el Boletín de la Convención de Basilea que se distribuyó durante la cop 10, en la ciudad de Cartagena, Jim Willis (secretario ejecutivo de los Convenios de Basilea, Rotterdam y Estocolmo),

63 Basel Action Network. Documental Exportar el Peligro: Asia bajo la Basura Al-Tec.

64 The CIA World FACtBook. India. Encontrado en: https://www.cia. gov/library/publications/the-world-factbook/geos/in.html. Consulta realizada el 4 de diciembre de 2011. 
afirma que el manejo ambientalmente adecuado de los desechos peligrosos es de gran importancia para lograr enfrentar las desigualdades que existen globalmente en cuanto a quienes son afectados por las consecuencias derivadas del mal manejo de estos desechos. Según WiIlis, en la actualidad el mal manejo de los desechos peligrosos tiene un impacto negativo excesivo sobre la población más pobre de los países en desarrollo. ${ }^{65}$ Esta situación de vulnerabilidad en la que se encuentran los países en desarroIlo frente a la amenaza de los desechos peligrosos para el medio ambiente y la salud humana, hace pensar que deberían tener una posición común para enfrentar esta problemática en las negociaciones internacionales.

Es también pertinente mencionar que la Declaración de Río sobre el Medio Ambiente y el Desarrollo determina 27 principios que buscan fortalecer la cooperación entre los Estados. Con relación a los países en desarrollo, resultan particularmente importantes dos: el Principio 3 que establece que "el derecho al desarrollo debe ejercerse en forma tal que responda equitativamente a las necesidades de desarrollo y ambientales de las generaciones presentes $y$ futuras" y el Principio 4 que afirma que "a fin de alcanzar el desarrollo sostenible, la protección del medio ambiente deberá constituir parte integrante del proceso de desarrollo y no podrá considerarse en forma aislada." Para ser coherentes con los principios antes citados, sería lógico que los países en desarrollo impulsaran la entrada en vigor de la Enmienda de la Prohi-

65 Unep, cop 10, Basel Convention. Basel Convention Bulletin. September, 2011. Pág. 1. bición. Como ya se explicó anteriormente, hay evidencia suficiente para demostrar que Colombia, Costa de Marfil y la India no cuentan con la capacidad para hacer un manejo adecuado de ciertos desechos peligrosos. Por lo tanto, en el contexto de estos países, la Enmienda de la Prohibición resulta ser un mecanismo coherente con el concepto de desarrollo sostenible, el cual consiste en satisfacer las necesidades de las generaciones presentes sin sacrificar las necesidades de las generaciones futuras. ${ }^{66}$

Por otro lado, el perfil económico de los países en estudio indica que gran parte de su población depende de la agricultura. Esta es otra razón por la cual deberían estar interesados en lograr que la Enmienda de la Prohibición entre en vigor. Lo anterior puede afirmarse ante la evidencia de que el manejo inadecuado de desechos peligrosos representa un riesgo para los recursos naturales y por ende amenaza la capacidad de estos países en desarrollo para cultivar alimentos saludables para los consumidores. En el caso de Colombia, el país cuenta con el privilegio de estar clasificado dentro del grupo de los cinco países con mayor biodiversidad en el mundo. ${ }^{67}$ Por lo tanto, la entrada en vigor de la Enmienda de la Prohibición le representa una oportunidad para proteger esta fortaleza reconocida mundialmente.

66 Centro de Información de las Naciones Unidas. Medio ambiente $y$ desarrollo sostenible. Encontrado en: http://www.cinu.mx/temas/ medio-ambiente/. Consulta realizada el 25 de abril de 2012.

67 Red de Desarrollo Sostenible de Colombia. Biodiversidad en Colombia. Encontrado en: http://www.rds.org.co/biodiversidad2/. Consulta realizada el 25 de abril de 2012. 


\section{B. Posibles factores económicos y políti- cos que han influido en las posiciones de los países en estudio frente a la Enmien- da de la Prohibición}

La India es un ejemplo claro de un país en desarrollo cuya posición frente a la Enmienda de la Prohibición ha sido influenciada por intereses económicos. Como se mencionó anteriormente, los altos niveles de pobreza en la India han llevado a que un número considerable de personas encuentre una forma de subsistencia en el desmantelamiento de desechos tecnológicos, a pesar de que ello les está ocasionando consecuencias perjudiciales para la salud y el entorno en el que habitan.

El Estado también ha realizado esfuerzos tendientes a promover el negocio del reciclaje de desechos tecnológicos en la India. Ejemplo de ello son la construcción de modernas plantas de reciclaje en terrenos estatales y el intento de desguace del portaaviones francés "Clemenceau" que finalmente impidió una decisión de la Corte Suprema de la India en el 2005. Ambos casos muestran, además, las limitaciones que tiene el país frente al manejo de desechos peligrosos. A pesar de la existencia de dichas limitaciones y siendo evidente que el desmantelamiento manual de desechos peligrosos representa un problema alarmante de salud pública, el Estado de la India se ha mostrado en contra de la entrada en vigor de la Enmienda de la Prohibición, lo cual resulta contradictorio con el hecho de haberla aceptado cuando se adoptó en 1995.
Según Jim Puckett, alrededor del año 1996 el gobierno de la India decidió que esta debía mostrarse como una economía poderosa y dejar de autodefinirse como un país en desarroIlo. En suma, Puckett afirma que la India dejó de ser solidaria con otros países en desarrollo y demostró estar convencida de que la ruta hacia el desarrollo implicaba soportar costos de externalidades, como por ejemplo, la polución y la importación de desechos. ${ }^{68}$

La oposición que ha mostrado la India a la entrada en vigor de la Enmienda de la Prohibición pudo notarse en el proceso de negociación que tuvo lugar en la cop 10 y que finalmente condujo a un acuerdo sobre la interpretación del artículo 17.5 del Convenio, a través de la denominada Decisión cLl. Es más, en el Grupo de Contacto dirigido por Osvaldo Álvarez (delegado de Chile), India pidió que se siguiera discutiendo la interpretación del párrafo 5 del artículo 17 del Convenio, mostrando resistencia a que la Enmienda de la Prohibición entre en vigor. ${ }^{69}$

En el caso de Chile también se puede apreciar la influencia de factores económicos en su posición con relación a la Enmienda de la Prohibición. Antes de ingresar a la OCDE en el 2010, Chile no la ratificó debido a que la prohibición de importar desechos peligrosos perjudicaba a la poderosa industria del cobre. Tras ingresar a la OCDE, ratificó la Enmienda de la Prohibición en

68 Entrevista a Jim Puckett, director ejecutivo de la ONG Basel Action Network, realizada a través de correo electrónico el 25 de abril de 2012.

69 Boletín de Negociaciones de la Tierra. Décima Reunión de la Conferencia de las Partes del Convenio de Basilea. Encontrado en: http://www.iisd.ca/vol20/enb2037s.html. Consulta realizada el 4 de marzo de 2012. 
el 2011: al ser parte de esta organización podrá seguir importando desechos peligrosos, lo cual le resulta beneficioso para la industria del cobre.

Por otro lado, la decisión de Chile de finalmente ratificar la Enmienda de la Prohibición posiblemente también estuvo impulsada por un interés político. Muchos de los países que son parte de la oCDE han expresado su interés en que la Enmienda de la Prohibición entre en vigor. Por consiguiente, la ratificación de la Enmienda al Convenio de Basilea por parte de Chile puede ser vista como una decisión política, a través de la cual quiere presentarse ante la comunidad internacional como un país que mantiene una posición común con los otros países miembros que desde hace años han estado impulsando la entrada en vigor de la Enmienda de la Prohibición. Por ejemplo, para el año 2006, la Enmienda de la Prohibición ya estaba siendo aplicada por varios Estados miembros de la Unión Europea, la cual ha manifestado su interés en acelerar su entrada en vigor. ${ }^{70} \mathrm{Al}$ respecto se debe aclarar que la mayoría de los países miembros de la Unión Europea hacen parte de la OCDE. ${ }^{71}$ Además, es importante recordar que Suiza (país miembro de la OCDE desde su creación en 1961) ha sido uno de los países que más ha promovido negociaciones tendientes a que la Enmienda de la Prohibición entre en vigor.

70 Informe de la Conferencia de las Partes del Convenio de Basilea en su octava reunión. Nairobi, 27 de noviembre - 1 de diciembre de 2006. Párrafo 34. Disponible en: http://archive.basel.int/meetings/cop/cop8/ docs/16s.pdf

71 OCDE. Acerca de la OCDE. Encontrado en: http://www.oecd.org/ pages/0,3417,es_36288966_36288120_1_1_1_1_1,00.html. Consulta realizada el 25 de abril de 2012 .
En el caso de Costa de Marfil, la inestabilidad política es probablemente el factor que más ha influenciado la posición del país frente a la Enmienda de la Prohibición, ya que aparte de la debilidad institucional derivada de la crisis política que enfrenta no se encuentran otras razones que permitan entender porqué todavía no la ha ratificado, a pesar de ser un ejemplo destacado de un país en desarrollo afectado por el manejo inadecuado de desechos peligrosos. Con respecto a esta situación, Jim Puckett afirma que las deficiencias en el funcionamiento del gobierno de Costa de Marfil constituyen la causa principal por la cual el país aún no ha ratificado la Enmienda de la Prohibición. ${ }^{72}$ La debilidad institucional antes descrita también se vio reflejada en el rol que tuvo su delegación en la cop 10, particularmente en las discusiones relacionadas con la entrada en vigor de la Enmienda de la Prohibición. Es más, según Jim Puckett, en las discusiones en las que él estuvo presente durante la cop 10, no notó ninguna intervención o influencia por parte de la delegación de Costa de Marfil. ${ }^{73}$

Colombia, por su parte, en las negociaciones multilaterales ambientales ha sido constante en mostrarse a favor de la entrada en vigor de la Enmienda de la Prohibición. ${ }^{74}$ No obstante, tampoco la ha ratificado. Es importante mencionar que ciertos intereses comerciales, posiblemente estuvieron detrás del archivo del proyecto de

72 Entrevista a Jim Puckett, director ejecutivo de la ong Basel Action Network, realizada a través de correo electrónico el 25 de abril de 2012.

$\begin{array}{ll}73 & \text { Ibidem. } \\ 74 & \text { Ibidem. }\end{array}$ 
ley que buscó la ratificación de la Enmienda la primera vez que se presentó ante el Congreso en el 2008. Esto sería un ejemplo de cómo las complejidades que existen en el funcionamiento del ordenamiento jurídico de cada país pueden llegar a ocasionar incoherencias entre lo que sucede en el derecho interno y la posición que se expresa en las negociaciones multilaterales ambientales. Lo anterior, teniendo en cuenta que el proceso de ratificación de un tratado internacional implica un procedimiento que debe llevarse a cabo internamente, de acuerdo con el ordenamiento jurídico de cada país. No obstante, debe recordarse que en septiembre de 2011 se presentó nuevamente un proyecto de ley ante el Congreso, buscando la ratificación de la Enmienda de la Prohibición. Se hubiera esperado que esta vez la iniciativa legislativa sí superara el trámite en el Congreso, lo cual era coherente con el rol que tuvo el país en la cop 10 y con la prohibición que existe en el ordenamiento jurídico colombiano con relación a la entrada de desechos peligrosos al territorio nacional.

\section{RESULTADOS DE LA 10 CONFEREN- CIA DE LAS PARTES DEL CONVENIO DE BASILEA REALIZADA EN CARTAGENA EN OCTUBRE DE 2011}

Los principales resultados de la cop 10 se resumen en las siguientes declaraciones de Paula Caballero, directora de Asuntos Económicos, Sociales y Ambientales del Ministerio de Relaciones Exteriores: “La mayor conclusión de este encuentro es la evidente voluntad política de los 117 países del cop-10. Se logró concientizar so- bre la necesidad del control de los desechos de manera multilateral entre países." 75

La cop 10 logró avances importantes con relación al tema de la Enmienda de la Prohibición. Siendo más preciso, los países participantes aprobaron una iniciativa liderada por los gobiernos de Suiza e Indonesia, que incluye, tras 15 años de negociaciones, un acuerdo que permitirá su entrada en vigor. Dicha iniciativa se basó en mejorar la efectividad de la Convención de Basilea y fue iniciada por los gobiernos de Indonesia y Suiza en la cop 8. Este esfuerzo fue apoyado por el gobierno de Colombia en la cop $10 .^{76}$

La denominada decisión “cLI" (Country-Led Initiative), que hace referencia a la iniciativa de Suiza e Indonesia, permitirá que la Enmienda de la Prohibición entre en vigor para aquellos países que quieran adherirse a ella. Gracias a esta decisión se logró llegar a un acuerdo sobre la interpretación del artículo 17(5) de la Convención, lo cual implica que la Enmienda de la Prohibición entrará en vigor cuando sea ratificada por 12 Estados adicionales a los que ya lo han hecho. Lo anterior se resume en el siguiente fragmento del Informe de la Conferencia de las Partes en el Convenio de Basilea de su décima reunión: “... sin perjuicio de otros acuerdos ambientales multilaterales, el párrafo 5 del artículo 17 del Convenio de Basilea se interpre-

75 El Universal. Conferencia de Basilea acuerda intensificar lucha contra residuos tóxicos. Encontrado en: http://www.eluniversal.com. co/cartagena/ambiente/conferencia-de-basilea-acuerda-intensificarlucha-contra-residuos-toxicos-49670. Noticia publicada el 22 de octubre de 2011. Consulta realizada el 4 de diciembre de 2011. over banning North-South movements of hazardous waste. Encontrado en: http://www.basel.int/. Consulta realizada el 4 de diciembre de 2011. 
te en el sentido de que, para que la enmienda entre en vigor, deben aceptarla tres cuartos de los países que eran Partes en el momento de su aprobación y hace notar que esta interpretación del párrafo 5 del artículo 17 no obliga a ninguna Parte a ratificar la Enmienda sobre la prohibición"77. Tanto Jim Puckett como Michael Stanley-Jones (oficial de Información Pública del PNUMA) coinciden en afirmar que Colombia, como sede de la cop 10, jugó un rol significativo en el proceso que permitió finalmente llegar a un acuerdo sobre la interpretación del artículo 17.5 del Convenio. ${ }^{78}$

Por otro lado, la decisión conocida como "cL" también contribuye a construir un régimen para aquellos países interesados en comercializar con desechos, en el que se minimicen los impactos sobre la salud y el medio ambiente y se aseguren condiciones adecuadas para los trabajadores. Frente a esto, Achim Steiner, director ejecutivo del Programa de las Naciones Unidas para el Medio Ambiente (PNUMA), manifestó que los resultados obtenidos en Cartagena ofrecen un ejemplo concreto de cómo las transformaciones en las acciones ambientales pueden servir para reducir la pobreza y promover un ambiente sano y equidad social. ${ }^{79}$

77 Informe de la Conferencia de las Partes en el Convenio de Basilea en su décima reunión. unEP/cHw.10/28. Cartagena, 17 de octubre - 21 de octubre de 2011. Pág. 33. Disponible en: http://archive.basel.int/ meetings/cop/cop10/documents/28s.pdf

78 Entrevista a Jim Puckett, director ejecutivo de la ong Basel Action Network. Entrevista a Michael Stanley-Jones, oficial de Información Pública del Programa de las Naciones Unidas para el Medio Ambiente. Ambas realizadas a través de correo electrónico el 25 de abril de 2012.

79 unep. BAsel Convention. Historic agreement ends 15 year deadlock over banning North-South movements of hazardous waste. Encontrado en: http://www.basel.int/. Consulta realizada el 4 de diciembre de 2011.
En la cop 10 se acordaron, además, guías técnicas que ayudarán a lograr un mejor manejo de basuras como las llantas usadas y los desechos electrónicos, incluyendo por ejemplo baterías y partes de computadores. Igualmente, se adoptó un Marco Estratégico para la Implementación de la Convención en el periodo de tiempo comprendido entre los años 2012 a $2021 .^{80}$ Dicho marco estratégico se enfoca en fortalecer el manejo adecuado de los desechos peligrosos como una contribución para proteger la salud humana, promover la sostenibilidad y erradicar la pobreza.

Con respecto a la problemática de la entrada de desechos peligrosos a países que no tienen la capacidad para darles un manejo adecuado, el Informe de la Conferencia de las Partes del Convenio de Basilea de su décima reunión ${ }^{81}$ establece lo siguiente:

si bien la enmienda del Convenio de Basilea aprobada por la Conferencia de las Partes en su decisión III/1 (Enmienda sobre la prohibición) es una de las formas de enfrentar ese problema, existen otras maneras de enfrentarlo de modo responsable, especialmente a través de una aplicación rigurosa del procedimiento de consentimiento fundamentado previo, el fortalecimiento del manejo ambientalmente racional y la promulgación de legislación nacional. ${ }^{82}$

80 New Strategic Framework for the Implementation of the Basel Convention for 2012-2021. UNEP/CHW.10/3. Disponible en: http://archive. basel.int/meetings/cop/cop10/documents/03e.pdf

81 Informe de la Conferencia de las Partes en el Convenio de Basilea en su décima reunión. UNEP/CHW.10/28. Cartagena, 17 de octubre - 21 de octubre de 2011. Pág. 32. Disponible en: http://archive.basel.int/ meetings/cop/cop10/documents/28s.pdf

82 Ibidem. 


\section{CONCLUSIONES}

Por medio de este trabajo se ha demostrado que existen marcadas diferencias de posición entre países en desarrollo, en el contexto de las negociaciones del sistema multilateral ambiental. Dichas diferencias han contribuido a que la Enmienda de la Prohibición aún no haya entrado en vigor, tras haber sido adoptada en 1995 como respuesta a la condición de vulnerabilidad de los países en desarrollo frente a los movimientos transfronterizos de desechos peligrosos.

Chile, Colombia, Costa de Marfil y la India son países en desarrollo con distintos grados de industrialización. No obstante, el contenido de este trabajo muestra que hay evidencia suficiente para demostrar que en estos países no se cuenta con los medios necesarios para importar ciertos desechos peligrosos y darles un manejo adecuado. A pesar de esta realidad, la India es ejemplo de un país que posteriormente a 1995 adoptó la posición consistente de mostrarse convencido de que el camino hacia el desarrollo implica soportar costos de externalidades como la polución e importar desechos, entre otros.

Es posible afirmar que cuando se adoptó la Enmienda de la Prohibición, en 1995, los países en desarrollo actuaron como un bloque. Sin embargo, los casos de los países objeto de este estudio indican que distintos factores económicos y políticos llevaron a que los países en desarrollo dejaran de tener una posición común frente a la Enmienda al Convenio.
Con respecto a Chile, la ratificación de la Enmienda de la Prohibición coincide con el ingreso del país a la oCDE. Este hecho indica que los intereses políticos y factores económicos, asociados principalmente con la industria del cobre chilena, han influido decisivamente en la posición que ha tenido el país frente a la Enmienda de la Prohibición.

Hay razones para pensar que los países en desarrollo con un mayor grado de industrialización, como es el caso de la India, son los que más se han opuesto a que la Enmienda entre en vigor, puesto que ellos mismos son responsables de la generación de una cantidad considerable de desechos peligrosos y a la vez se benefician del negocio del reciclaje. Sin embargo, llama la atención que un país como Costa de Marfil, cuya economía es altamente dependiente de la agricultura, tampoco la haya ratificado, lo cual pone de manifiesto cómo la debilidad institucional influye en la posición de un país en las negociaciones multilaterales ambientales.

Adicionalmente a la debilidad institucional, las complejidades al interior del ordenamiento jurídico de cada país también están asociadas con la demora de la entrada en vigor de la Enmienda de la Prohibición. Colombia, a pesar de haber sido constante en mostrarse a favor en las negociaciones multilaterales ambientales tampoco la ha ratificado pues las iniciativas legislativas que se han presentado ante el Congreso no han superado el trámite previsto en el ordenamiento jurídico interno. Con los exitosos resultados que se alcanzaron en la cop 10 con relación a impulsar la entrada en vigor de la Enmienda, se 
esperaría que el último proyecto de ley que se presentó ante el Congreso de Colombia en septiembre de 2011, tendiente a la ratificación de la Enmienda, sí supere dicho trámite. ${ }^{83}$

Tras 15 años de discusiones, los resultados obtenidos en la cop 10 realizada en Cartagena son históricos puesto que finalmente se llegó a un acuerdo sobre la interpretación del párrafo 5 del artículo 17 del Convenio. Además, el consenso logrado es un avance importante con relación al compromiso que deben tener los países en desarrollo de actuar de manera coherente con el Principio 4 de la Declaración de Río sobre el Medio Ambiente y el Desarrollo. Dicho principio establece que "a fin de alcanzar el desarrollo sostenible, la protección del medio ambiente deberá constituir parte integrante del proceso de desarrollo y no podrá considerarse en forma aislada." ${ }^{84}$ En este sentido, es un gran triunfo que inclusive países como la India, que habían sido claros en expresar su resistencia a la entrada en vigor de la Enmienda de la Prohibición, finalmente no hayan impedido el acuerdo al que se llegó en la cop 10 sobre la interpretación del artículo 17.5 del Convenio. La adopción de esta decisión se debió a un deseo de conciliar la discusión que se prolongó por tantos años y también posiblemente a la no aplicación de la Enmienda para aquellos que no la ratifiquen. Por lo tanto, el haber logrado dicha conciliación en la cop 10 puede contribuir a que hacia el futuro los países en desarrollo se acerquen a la posibilidad de tener una posición común en las negociaciones multilaterales ambientales.
83 La Enmienda aún no ha sido ratificada por Colombia de acuerdo con la página web del Convenio de Basilea. El proyecto de ley fue aprobado en segundo debate en el Congreso, el 29 de agosto de 2012. Quedaría pendiente el traslado a la otra cámara y en caso de ser aprobado allí, la sanción presidencial. Por lo tanto, si bien el proyecto ha sido aprobado en dos debates en una Cámara, todavía no ha superado en su totalidad el trámite ante el Congreso puesto que faltaría la aprobación por la otra cámara. En el siguiente link se señala en qué etapa se encuentra el proyecto respecto del tramite que debe superar: http://www.congresovisible.org/proyectos-deley/por-medio-de-la-cual-se-aprueba-la-enmienda-al-convenio-debasilea-sobre-el-control-de-los-movimientos-transfronterizos-dedesechos-peligrosos-y-su-eliminacion-del-22-de-marzo-de-1989adoptada-por-la-tercera-reunion-de-la-conferencia-de-las-partes-enginebra-el-22-de-septiembre-de-1995-convenio-sobre-desechospeligrosos $/ 6429 / \#$ tab $=2$
84 Declaración de Río sobre el Medio Ambiente y el Desarrollo. Principio 4. 
Países Partes que han ratificado la Enmienda de la Prohibición ${ }^{85}$

Número total de ratificaciones: 73

\begin{tabular}{|c|c|}
\hline Estados Parte del Convenio & $\begin{array}{c}\text { Fecha de ratificación } \\
\text { de la Enmienda de la } \\
\text { Prohibición }\end{array}$ \\
\hline Albania & 27.10 .05 \\
\hline Andorra & 23.07 .99 \\
\hline Argentina & 19.09.11 \\
\hline Austria & 17.10 .99 \\
\hline Bahréin & 25.07 .05 \\
\hline Bélgica & 20.06 .03 \\
\hline Bolivia & 31.03 .05 \\
\hline Botsuana & 17.06 .04 \\
\hline Brunei Darussalam & 16.12 .02 \\
\hline Bulgaria & 15.02 .00 \\
\hline Chile & 12.08 .09 \\
\hline China & 01.05 .01 \\
\hline Islas Cook & 29.06 .04 \\
\hline Chipre & 07.07 .00 \\
\hline República Checa & 28.02 .00 \\
\hline Dinamarca & 10.09 .97 \\
\hline Ecuador & 06.03 .98 \\
\hline Egipto & 27.01 .04 \\
\hline Estonia & 02.08 .01 \\
\hline Etiopía & 08.10 .03 \\
\hline Unión Europea & 30.09 .97 \\
\hline Finlandia & 05.09 .96 \\
\hline Francia & 18.11 .03 \\
\hline Gambia & 07.03 .01 \\
\hline Estado Parte del Convenio & $\begin{array}{c}\text { Fecha de ratificación } \\
\text { de la Enmienda de la } \\
\text { Prohibición }\end{array}$ \\
\hline Alemania & 24.05 .02 \\
\hline Ghana & 09.06 .05 \\
\hline Grecia & 12.07 .10 \\
\hline Hungría & 25.05 .04 \\
\hline Indonesia & 24.10 .05 \\
\hline Irlanda & 13.11 .09 \\
\hline Italia & 03.03 .09 \\
\hline Jordán & 06.12 .04 \\
\hline Kenia & 09.09 .09 \\
\hline Kuwait & 12.05 .06 \\
\hline Letonia & 18.12.03 \\
\hline
\end{tabular}

85 Esta tabla se encuentra en la página web oficial del Convenio de Basilea. Disponible en: http://www.basel.int/Countries/StatusofRatifications/ BanAmendment/tabid/1344/Default.aspx 


\begin{tabular}{|c|c|}
\hline Lesoto & 22.02 .12 \\
\hline Liberia & 16.09 .05 \\
\hline Liechtenstein & 20.05 .03 \\
\hline Lituania & 07.11 .03 \\
\hline Luxemburgo & 14.08 .97 \\
\hline Malasia & 26.10 .01 \\
\hline Malta & 12.12.11 \\
\hline República de Mauricio & 09.11 .04 \\
\hline Montenegro & 22.11 .06 \\
\hline Moroco & 10.09 .04 \\
\hline Países Bajos & 22.01 .01 \\
\hline Nigeria & 24.05 .04 \\
\hline Noruega & 16.07 .97 \\
\hline Omán & 17.05 .04 \\
\hline Panamá & 07.10 .98 \\
\hline Paraguay & 28.08 .98 \\
\hline Polonia & 29.01 .03 \\
\hline Portugal & 30.10 .00 \\
\hline Qatar & 28.02 .02 \\
\hline República de Moldavia & 28.10 .08 \\
\hline Rumania & 17.07 .02 \\
\hline Estados Parte del Convenio & $\begin{array}{c}\text { Fecha de ratificación } \\
\text { de la Enmienda de la } \\
\text { Prohibición }\end{array}$ \\
\hline Serbia & 22.11.02 \\
\hline Eslovaquia & 11.09 .98 \\
\hline Eslovenia & 01.12 .04 \\
\hline España & 07.08.97 \\
\hline Sri Lanka & 29.01 .99 \\
\hline St. Lucía & 22.01 .02 \\
\hline Suecia & 10.09 .97 \\
\hline Suiza & 07.11 .02 \\
\hline República Árabe Siria & 05.10 .04 \\
\hline $\begin{array}{l}\text { Ex República Yugoslava de } \\
\text { Macedonia }\end{array}$ & 18.11.04 \\
\hline Trinidad \& Tobago & 12.01 .00 \\
\hline Tunes & 26.10 .99 \\
\hline Turquía & 27.08 .03 \\
\hline Reino Unido & 13.10 .97 \\
\hline Tanzania & 26.08 .02 \\
\hline Uruguay & 10.03 .99 \\
\hline Zambia & 27.07 .11 \\
\hline
\end{tabular}


Países presentes cuando se adoptó la Enmienda de la Prohibición, cuáles ya la ratificaron y cuáles aún no lo han hecho86:

\begin{tabular}{|c|c|}
\hline \multicolumn{2}{|c|}{ Países Partes presentes cuando se adoptó la Enmienda de la Prohibición en 1995} \\
\hline Países que ya ratificaron la Enmienda & $\begin{array}{l}\text { Países que aún no han ratificado la Enmienda (se requiere } \\
\text { la ratificación de } 12 \text { de estos países para que la Enmienda } \\
\text { entre en vigor). }\end{array}$ \\
\hline $\begin{array}{l}\text { Argentina, Australia, Bélgica, Chile, China, Chipre, } \\
\text { República Checa, Dinamarca, Ecuador, Egipto, } \\
\text { Estonia, Comunidad Europea, Finlandia, Francia, } \\
\text { Alemania, Grecia, Hungría, Indonesia, Irlanda, } \\
\text { Italia, Jordán, Kuwait, Letonia, Liechtenstein, } \\
\text { Luxemburgo, Malasia, República de Mauricio, } \\
\text { Países Bajos, Nigeria, Noruega, Omán, Panamá, } \\
\text { Polonia, Portugal, Qatar, Rumania, Santa Lucía, } \\
\text { Eslovaquia, Eslovenia, España, Sri Lanka, Suecia, } \\
\text { República Árabe Siria, Trinidad y Tobago, Turquía, } \\
\text { Reino Unido, Tanzania, Uruguay, Zambia. }\end{array}$ & $\begin{array}{l}\text { Antigua y Barbuda, Australia, Bahamas, Bangladesh, } \\
\text { Brasil, Canadá, Costa Rica, Costa de Marfil, Croacia, } \\
\text { Cuba, El Salvador, Guatemala, Islandia, India, Irán, Israel, } \\
\text { Japón, Líbano, Malawi, México, Namibia, Nueva Zelandia, } \\
\text { Paquistán, Perú, Filipinas, República de Corea, Federación } \\
\text { Rusa, Arabia Saudita, Senegal, Seychelles, Sur África, } \\
\text { Vietnam. }\end{array}$ \\
\hline Total: 50 & Total: 32 \\
\hline
\end{tabular}

\section{Bibliografía}

\section{Doctrina:}

BIRNIE, Patricia y Boyle, Alan. International Law \& The Environment. Second Edition. New York: Oxford University Press, 2002.

Guzmán, Patricia. Introducción al análisis económico del derecho ambiental. Primera Edición. Bogotá: Universidad Externado de CoIombia. Editorial Cordillera S.A.C, 2006.

Hardin, Garrett. Derecho ambiental y justicia Social. Bogotá: Siglo del Hombre Editores, 2009.

86 BAN. The Basel Ban Amendment: Just Say Now! Briefing Paper 4. October 2011.
KuMmer, Katharina. International Management of Hazardous Wastes: The Basel Convention and Related Legal Rules. New York: Oxford University Press, 1999.

Kummer, Katharina. Convenio de Basilea sobre el control de los movimientos transfronterizos de los desechos peligrosos y su eliminación. United Nations. Audiovisual Library of International Law, 2011. En: http://untreaty.un.org/ cod/avl/pdf/ha/bcctmhwd/bcctmhwd_s.pdf . Consulta realizada el 21 de abril de 2012.

Uribe, Diego y Cárdenas, Fabián Augusto. Derecho Internacional Ambiental. Bogotá: Universidad Jorge Tadeo Lozano, 2010. 
Instrumentos jurídicos

Constitución Política de Colombia de 1991. Artículo 81.

Convenio de Basilea sobre el control de los movimientos transfronterizos de los desechos peligrosos y su eliminación.

Decisión III/1 del 22 de septiembre de 1995, adoptada durante la Tercera Reunión de la Conferencia de las Partes (cop 3) que tuvo lugar en Ginebra.

Declaración de Río sobre el Medio Ambiente y el Desarrollo, 1992.

Congreso de Colombia. Ley 1252 de 2008 de la República de Colombia.

Congreso Nacional de Chile. Decreto Supremo No. 264 del 16 de abril de 2011.

Exposición de Motivos del proyecto de ley presentado por la ministra de Relaciones Exteriores y la ministra de Ambiente, Vivienda y Desarrollo Territorial, ante el Congreso de Colombia el 7 de septiembre de 2011, con el objetivo de que se ratifique la Enmienda al Convenio de Basilea.

Senado de la República de Colombia. Proyecto de Ley número 151 de 2008.

\section{Entrevistas y reuniones}

Entrevista a Alba Ávila, profesora de la Facultad de Ingeniería Electrónica de la Universidad de los Andes. Septiembre 7 de 2011.
Entrevista a Jim Puckett, director ejecutivo de la oNg Basel Action Network. Abril 25 de 2012.

Entrevista a Michael Stanley-Jones, oficial de Información Pública del PNUMA. Abril 25 de 2012.

Reunión del GRULAC. Octubre 16 de 2011. Cartagena de Indias (Colombia), en el marco de la cop 10.

Material que se distribuyó en la 10ạ Reunión de la Conferencia de las Partes del Convenio de Basilea, realizada en Cartagena de Indias del 17 al 21 de octubre de 2011

Basel Action Network. The Basel Ban Amendment: Just Say Now! Briefing Paper 4. October 2011.

Basel Action Network. Documental Exportar el peligro: Asia bajo la Basura Al-Tec.

Basel Action Network. Documental El Basurero Digital: La exportación del segundo uso y el abuso a África.

Pnuma. Convenio de Basilea. Manual de capacitación sobre el tráfico ilícito para los servicios de aduanas y organismos encargados de hacer cumplir la ley.

PNUMA. El tráfico ilícito en el marco del Convenio de Basilea. Actualizado en diciembre 2010.

Unep. Unilted Nations Environment Programme. Basel Convention. Waste without frontiers. Global trends in generation and transboundary movements of hazardous wastes and other 
wastes. Analysis of the data from national reporting to the Secretariat of the Basel Convention for the years 2004-2006. Document prepared by Kees Wielenga for the Secretariat of the Basel Convention. Geneva, 2010.

- unep, cop 10, Basel Convention. Basel Convention Bulletin. September, 2011.

\section{Documentos, artículos y noticias encontrados en} Internet

Amnesty International. Costa de Marfil: El dinero perdido debe llegar a las víctimas del vertido tóxico de Trafigura. http://www.amnesty.org/ en/node/26240. Artículo publicado el 19 de agosto de 2011. Consulta realizada el 4 de diciembre de 2011.

Banco Interamericano de Desarrollo. Fortalecimiento de la gestión ambiental para cumplimiento de acuerdos multilaterales ambientales (AмUмA's). http://idbdocs.iadb.org/wsdocs/ getdocument.aspx?docnum=1001426. Artículo publicado en mayo de 2007. Consulta realizada el 3 de marzo de 2012.

BBC mundo. Costa de Marfil, de país modelo a enfermo africano. http://latercera.com/noticia/mundo/bbc-mundo/ internacional/2011/01/1434-335488-9bbc-costa-de-marfil-de-pais-modelo-a-enfermo-africano.shtml. Artículo publicado el 4 de enero de 2011. Consulta realizada el 25 de abril de 2012.

BBC NEWs. Growing concern over India's e-waste. http://news.bbc.co.uk/2/hi/south_ asia/3307815.stm. Artículo publicado el 12 de diciembre de 2003. Consulta realizada el 3 de diciembre de 2011.

Bнowmıck, Nilanjana. Time World. Is India's EWaste problem spiraling out of control? http://www.time.com/time/world/article/0,8599,2071920,00.html. Artículo publicado el 23 de mayo de 2011. Consulta realizada el 3 de diciembre de 2011.

Boletín de Negociaciones de la Tierra. Décima reunión de la Conferencia de las Partes del Convenio de Basilea. http://www.iisd.ca/ vol20/enb2037s.html. Consulta realizada el 4 de marzo de 2012.

BuLska, Rummel. The Basel Convention on the control of transboundary of hazardous wastes and their disposal. http://www.inece. org/1stvol1/rummel-bulska.htm. Consulta realizada el 10 de septiembre de 2011.

Centro de Información de las Naciones Unidas. Medio Ambiente y Desarrollo Sostenible. http:// www.cinu.mx/temas/medio-ambiente/. Consulta realizada el 25 de abril de 2012.

CIA World FactBook. Chile. https://www.cia.gov/ library/publications/the-world-factbook/ geos/br.html. Consulta realizada el 4 de diciembre de 2011.

CIA World FACTBOok. Cote d'Ivoire. https://www. cia.gov/library/publications/the-world-factbook/geos/iv.html. Consulta realizada el 4 de diciembre de 2011. 
CIA World Factbook. Colombia. https://www.cia. gov/library/publications/the-world-factbook/ geos/co.html. Consulta realizada el 4 de diciembre de 2011.

CIA World FACTBOok. India. https://www.cia.gov/ library/publications/the-world-factbook/ geos/in.html. Consulta realizada el 4 de diciembre de 2011.

Ecoticias.com. Colombia será la sede de la conferencia internacional destinada a promover la reducción de los desechos peligrosos y su reutilización. http://www.ecoticias.com/residuos-reciclaje/40780/. Artículo publicado el 23 de enero de 2011. Consulta realizada el 10 de septiembre de 2011.

E-waste in India: A Growing Industry and Environmental Threat. http://www.treehugger.com/ clean-technology/e-waste-in-india-a-growingindustry-environmental-threat.html. Artículo publicado el 9 de octubre de 2007. Consulta realizada el 3 de diciembre de 2011.

Hoffmann, Veena Jha. Achieving objectives of multilateral environmental agreements: a package of trade measures and positive measures. http://www.unctad.org/trade_ env/docs/booksum.pdf. Consulta realizada el 10 de septiembre de 2011.

Informe de la Conferencia de las Partes en el Convenio de Basilea sobre la labor de su décima reunión. Cartagena, 17 a 21 de octubre de 2011. UNEP/CHW.10/28. http:// archive.basel.int/meetings/cop/cop10/ documents/28s.pdf
Informe de la Conferencia de las Partes en el Convenio de Basilea sobre la labor de su séptima reunión. Ginebra, 25 a 29 de octubre de 2004. UNEP/CHW.7/33. http://archive.basel. int/meetings/cop/cop7/docs/33s.pdf

Informe de la Conferencia de las Partes en el Convenio de Basilea sobre la labor de su octava reunión. Nairobi, 27 de noviembre - 1 de diciembre de 2006. UNEP/CHW.8/16. http:// archive.basel.int/meetings/cop/cop8/docs/16s.pdf

Informe de la Conferencia de las Partes en el Convenio de Basilea sobre la labor de su novena reunión. Bali, 23 a 27 de junio de 2008. UNEP/CHW.9/39. http://archive.basel.int/meetings/ cop/cop9/docs/39s-rep.pdf

Informe del Grupo de Trabajo del Convenio de Basilea. Sexta sesión. Ginebra, 3 a 7 de septiembre de 2007. UNEP/CHW/OEWG/6/29. http://archive.basel.int/meetings/oewg/ oewg6/docs/29s.pdf

JoHnstone, Nick. The implications of the Basel Convention for developing countries: the case of trade in non-ferrous metalbearing waste. ftp://124.42.15.59/ ck/201102/165/032/254/236/The\%20 implications\%20of\%20the\%20Basel\%20 Convention\%20for\%20developing\%20countries $\% 20$ the $\% 20$ case $\% 20$ of $\% 20$ trade $\% 20$ in\%20non-ferrous \%20metal-bearing\%20waste.pdf. Artículo publicado el 16 de enero de 2011. Consulta realizada el 10 de septiembre de 2011. 
oCDE. Acerca de la oCDE. http://www.oecd.org/ pages/0,3417,es_36288966_36288120_ 1_1_1_1_1,00.html. Consulta realizada el 25 de abril de 2012.

Convenio de Basilea. http://www.basel.int/

El UnIVERSAl. Conferencia de Basilea acuerda intensificar lucha contra residuos tóxicos. http://www.eluniversal.com.co/cartagena/ ambiente/conferencia-de-basilea-acuerda-intensificar-lucha-contra-residuos-toxicos-49670. Noticia publicada el 22 de octubre de 2011. Consulta realizada el 4 de diciembre de 2011.

Portafolio. Colombia en la oeCD: Un propósito nacional. http://www.portafolio.co/archivo/documento/CMS-4117869. Consulta realizada el 3 de marzo de 2012.

Puckett Jim. The Basel Ban: A Triumph Over Business-As-Usual. http://www.ban.org/about_ basel_ban/jims_article.html. Consulta realizada el 10 de septiembre de 2011.
Red de Desarrollo Sostenible de Colombia. Biodiversidad en Colombia. http://www.rds.org.co/ biodiversidad2/. Consulta realizada el 25 de abril de 2012

Secretariat of the Basel Convention. Our sustainable future: the role of the Basel Convention. http://www.basel.int/pub/broch090508. pdf. Consulta realizada el 5 de noviembre de 2011.

Schutz, Gabriel y Pimienta, Marta. Grupo de Direitos Humanos e Saúde Helena Besserman (DIHS), Escuela Nacional de Salud Pública Sergio Arouca (ENSP), Fundación Oswaldo Cruz (FIOCRUZ). Transporte de residuos peligrosos en Brasil y la Convención de Basilea. http:// guajiros.udea.edu.co/fnsp/Conferencia/ memorias/Viernes/Presentaciones/Salon2/ R2/P5/resumen.pdf. Consulta realizada el 4 de diciembre de 2011.

unep. Basel Convention. Historic agreement ends 15 year deadlock over banning North-South movements of hazardous waste. http://www. basel.int/. Consulta realizada el 4 de diciembre de 2011. 